ص ص[

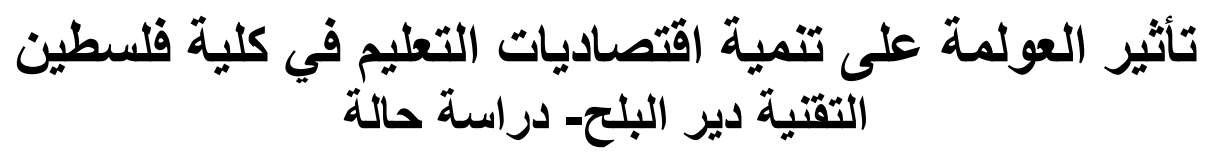

$$
\begin{aligned}
& \text { الدكتور وفيق حلمي الأغا } \\
& \text { أستاذ مشارك قسم أدارة الأعمال } \\
& \text { كلية الاقتصاد والعلوم الإدارية جامعة الأزهر } \\
& \text { غزة - فلسطين }
\end{aligned}
$$

w_el_agha@yahoo.com

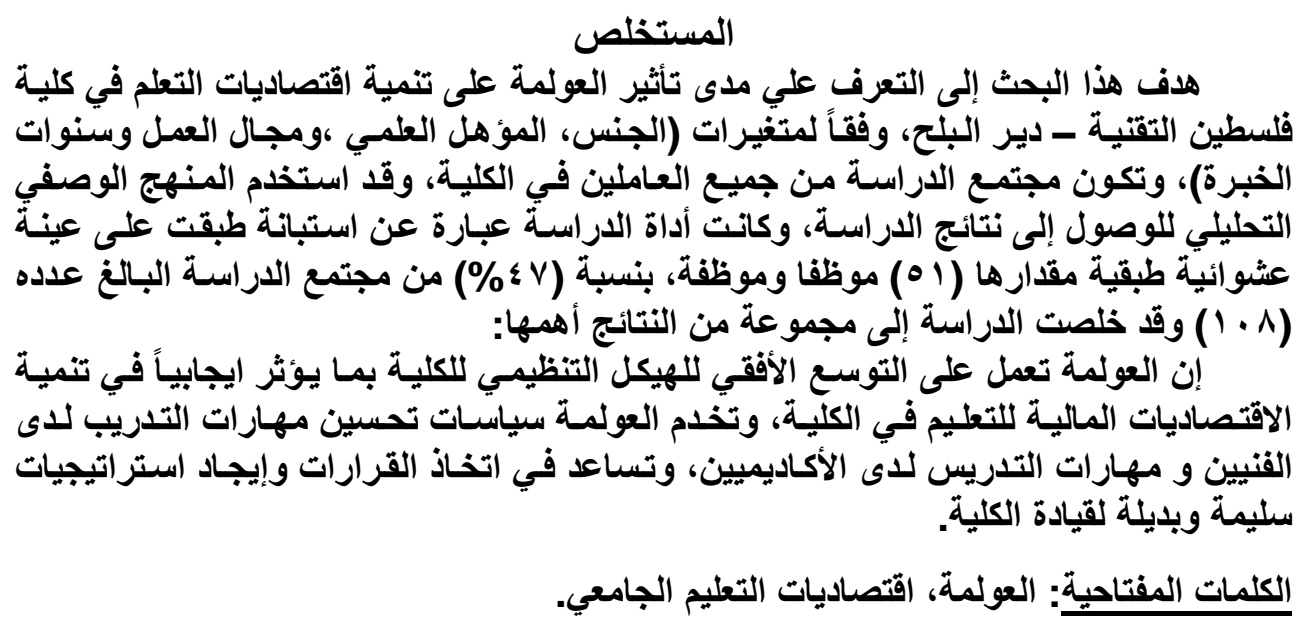

\title{
The Effect of Globalization on the Development of Pedagological Economics in Palestine Technical College in Dair-Elbala (Case Study)
}

\author{
Wafiq H. Al-Agha (PhD) \\ Department of Business Administration \\ Al-Azhar University -Ghaza
}

\begin{abstract}
The objective of the research is to identify the impact of globalization on the development of economics of learning in Palestine Technical College - Deir El-Balah, according to the variables of gender, qualifications, the area of employment and years of experience. A community study of all employees has been done using descriptive analytical approach to reach the results of the study. A questionnaire was applied on a random sample of (51) staff members, or (47\%) of the total number of staff members (108). The study concluded that globalization is working for the horizontal expansion of the organizational
\end{abstract}

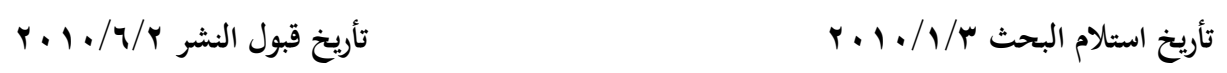


structure of the College, including a positive impact on the development of economies of financial education at the college and serve the globalization policies that improve the skills training of technicians and teaching skills have academics and help in decision-making and the creation of sound strategies and an alternative to the leadership of the college.

Key Words: Globalization, Pedagological Economics.

المقدمة

توصف العولمة بأنها زمن التحولات والتغيرات السريعة لتعميم الاتجاهات والقيم

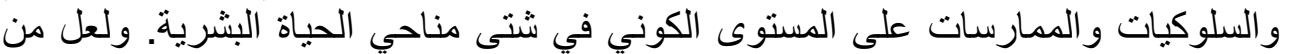

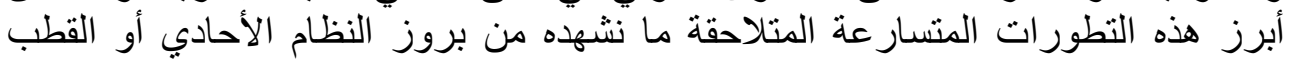

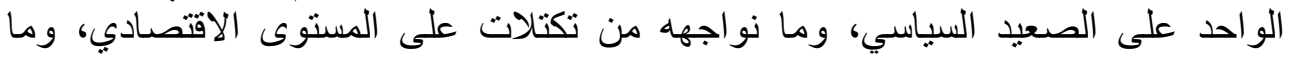

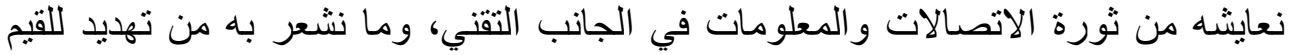

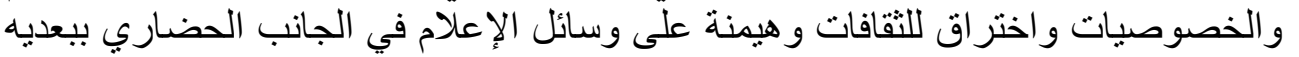

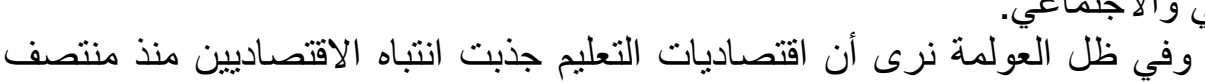

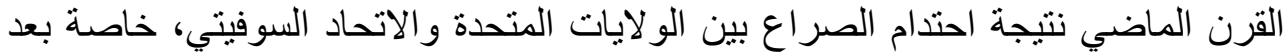

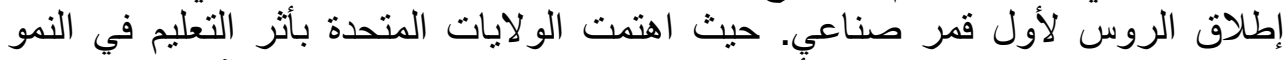

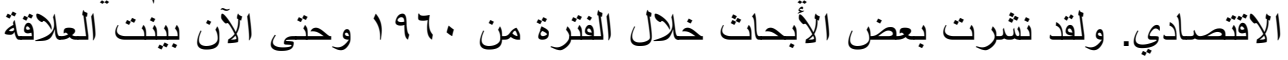

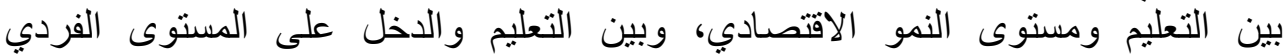

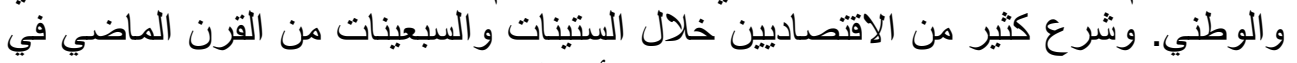

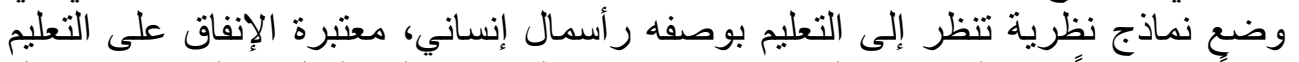

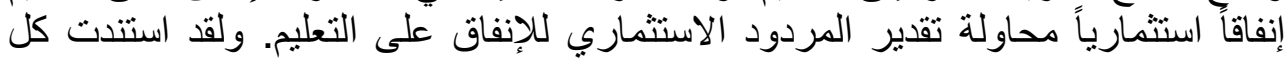

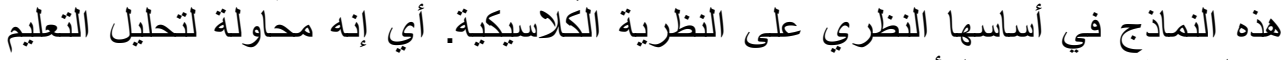

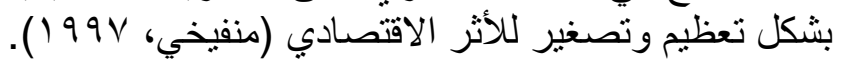

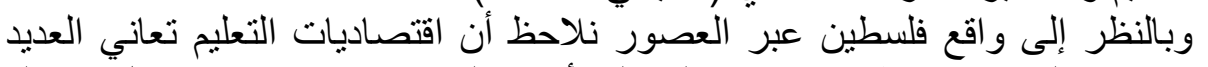

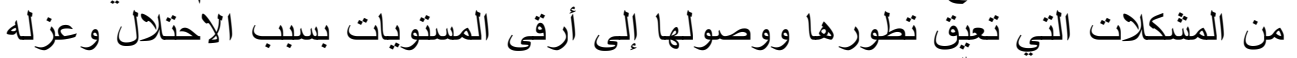

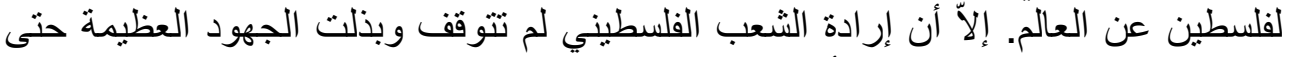

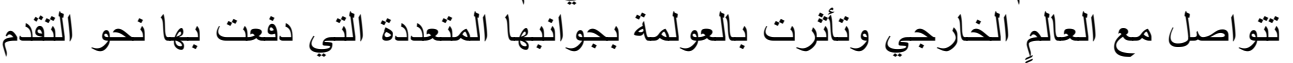
و إن كان متو اضعاً. كان ذللك الدافع الرئيس الذي دفع الباحث للخوض في هذا المجال لدراسته واستخلاص العبر منه. و استتاداً إلى ما سبر مئ يبرز التساؤل الرئيس لمشكلة البحث: ما هو أثر العولمة على تنمية اقتصاديات التعليم التقني في كلية فلسطين التقنية لتئـ دير 


\section{[1vo] الأن}

ا. توجد علاقة ذات دلالة إحصائية عند مستوى دلالة (0. . •) بين العولمة و الاقتصاديات المادية للتعليم في كلية فلسطين التقنية ــ دير البلح.

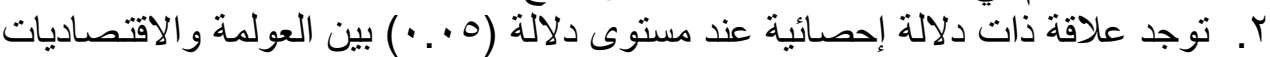
البشرية للتعليم في كلية فلسطين التقنيةــ دير البلح.

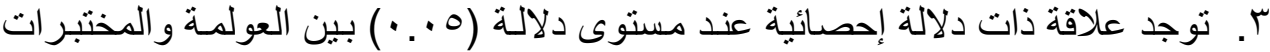

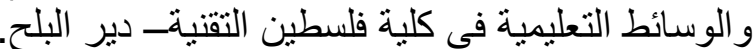

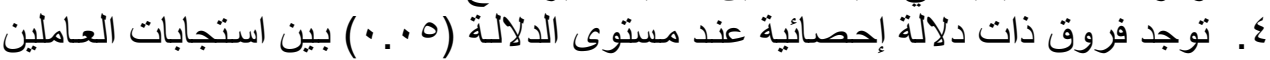

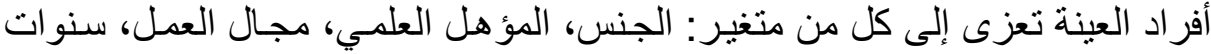
الخبرة، بالنسبة لمجالات الاستبانة الثناثثة.

$$
\text { أهداف البحث البحث إلى التعرف على: }
$$

ا. . العولمـة و علاقتهـا بالاقتصـاديات الماديـة للتعليم التقني في كليـة فلسطين التقنيـة دير البلح. r. . العولمـة و علاقتها بالاقتصاديات البشرية للتعليم التقني في كلية فلسطين التقنية- دير r. العولمة و علاقتها بالإمكانيات التكنولوجية للتعليم التقني في كلية فلسطين التقنية- دير ع. العولمة و علاقتها بالتنمية الثاملة في فلسطين.

تكمن أهمية البحث في التعرف على العولمة و علاقتها بتطوير وتتمية قدرات الأفر اد

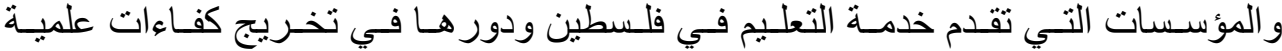
متخصصة ذات كفاءة وجودة عالية في كافة مجالات التعليم، وقدرة المؤسيسات فلى على خوض المعركة التنافية على مستوى الوطن وات والعة فيالم.

$$
\text { تتحدد الدر اسة بالحدود الآتية: }
$$

1. الحدود الموضو عية: اقتصر البحث على تحديد أثر العولمة في تنمية اقتصاديات التعليم التقني في كلية فلسطين التقنية ـ دير البلح من وجهة نظئ نظر الفئة المستهدفة. r r. الحدود المكانية: تم تطبيق البحث على كلية فلسطين التقنية-دير البلح.

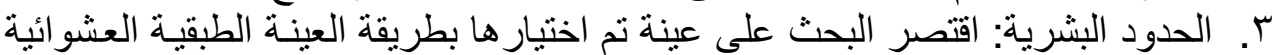

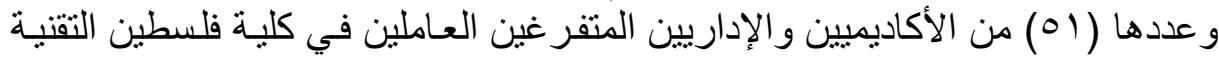


ويمكن القول (كما يؤكد السيد ياسين) إن صباغة تعريف دقيق للعولمـة تبدو مسألة

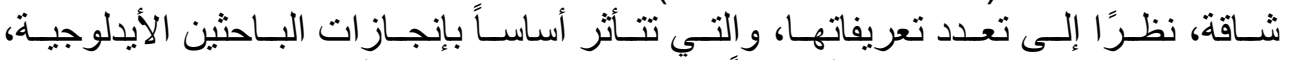

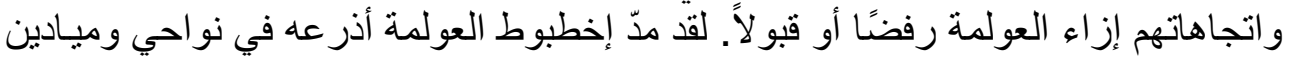

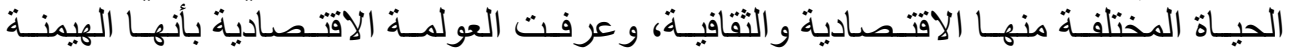

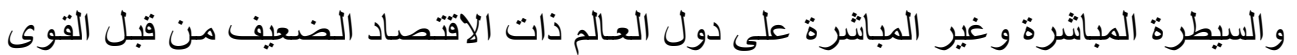

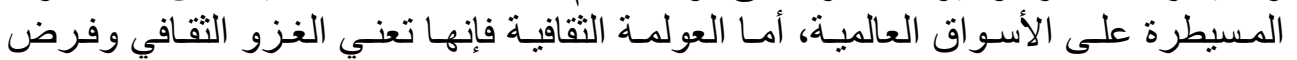

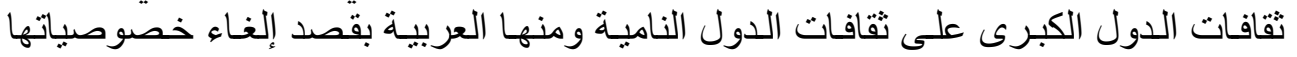

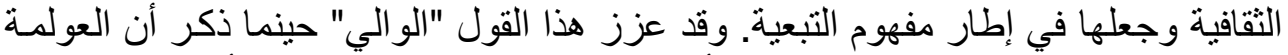

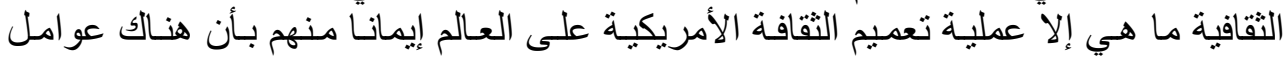
سلبية في الثقافات الأخرى للبلدان.

اقتصاديات التعليم Economics Of Education أو اقتصاد التعليم أو اقتصاد التربية اقتصاديات التعليم و التعليم، و هو فرع من فروع علم الاقتصاد يبحث في الجوانب الاقتصادية للعملية التربوية التبادية

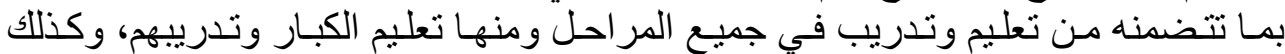

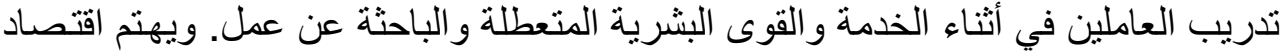

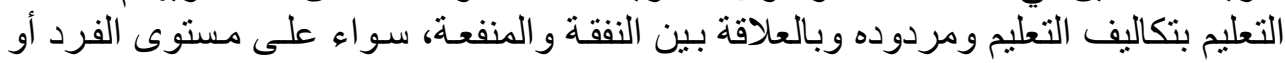
على مستوى الاقتصاد الوطني. الوني.

ويتبنى الباحث التعريف الآتي لاقتصاديات التعليم وهو: "دراسة كيفية اختيار

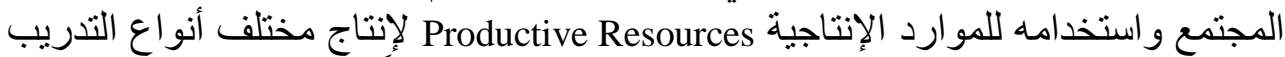

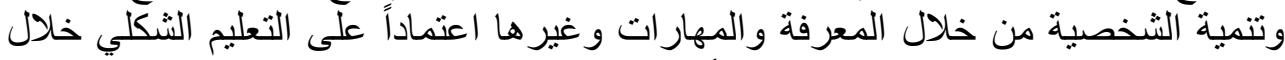
فترة زمنية محددة وكيفية توزيعها بين الأفر اد و المجمو عات في الحاضر و المستقبل".

\section{كلية فلسطين التقنية}

تأسست كلية فلسطين التقنية عام (ب9 (99) تحت اسم كلية العلوم المهنية، وتقع الكلية

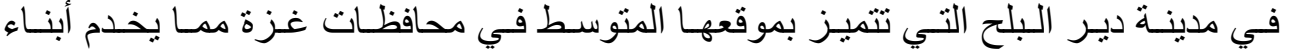

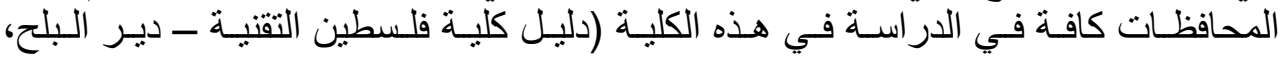

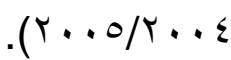

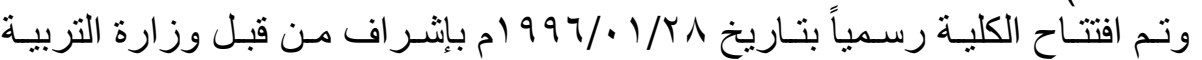

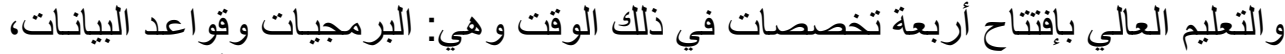

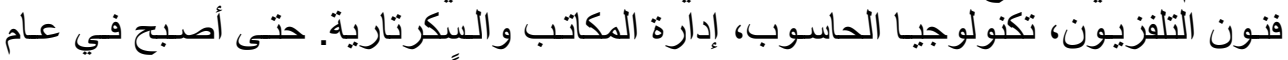

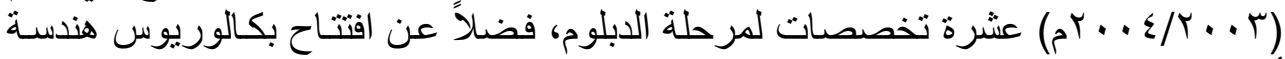

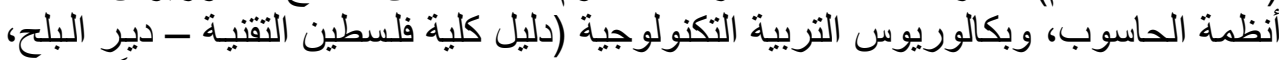

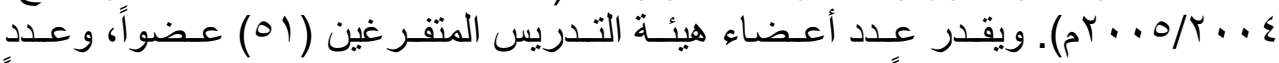

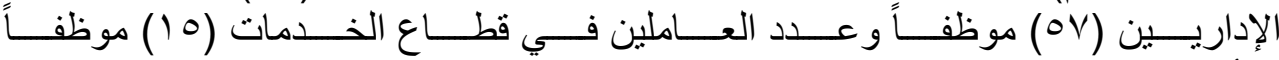

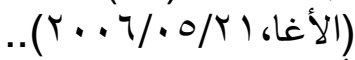

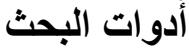




\section{$[1 \mathrm{l}$}

استخدم الباحث الاستبانة بوصفها أداة بحث لقياس أثر العولمة على تنميـة اقتصاديات التعليم في كلية فلسطين التقنية- دير البلح، وذلك بعرضها على بعض التحانية المحكمين ذوي الخبرة

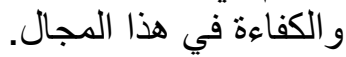

الاسات السابقة

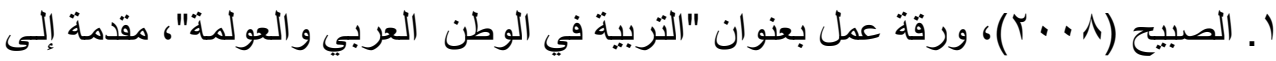

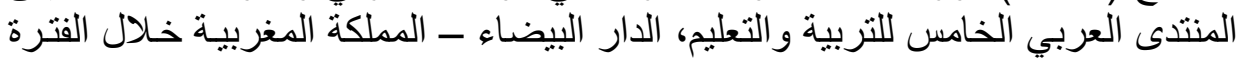

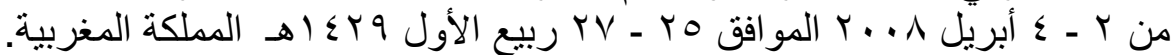

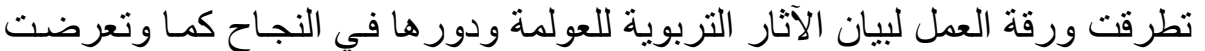

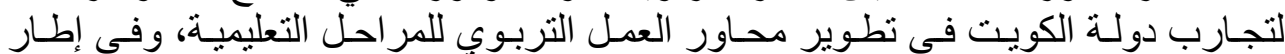

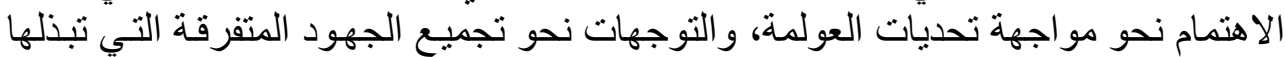

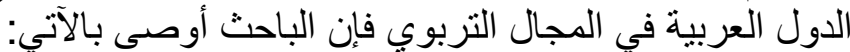
• استيعاب التربية لمفاهيم العولمة واتجاهاتها الايجابية وتوظيفها لبالياء لبناء نظام تربوي متطور

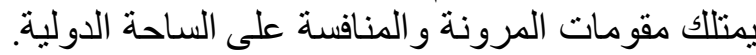

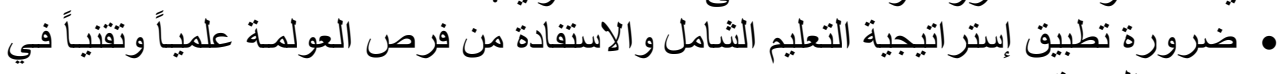

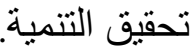

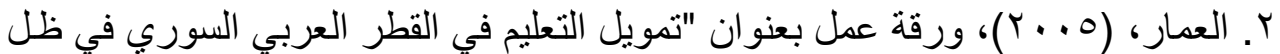

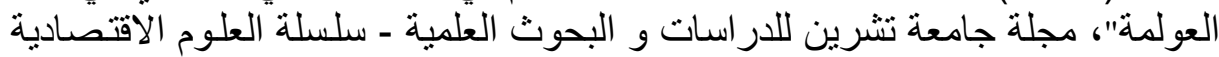

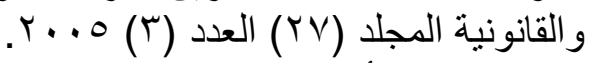

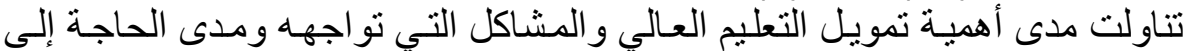

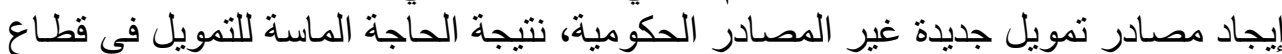

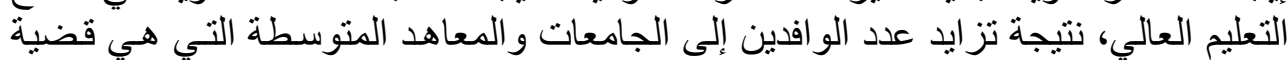

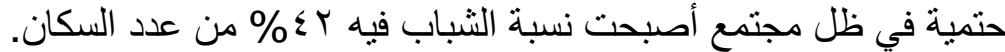

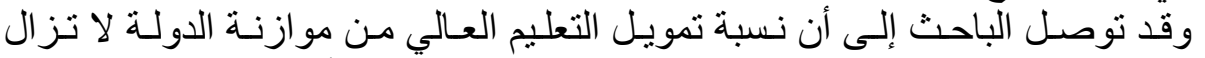

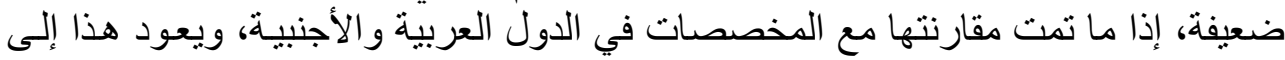

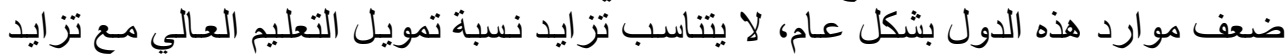

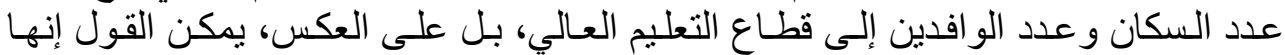
تنتاقص.

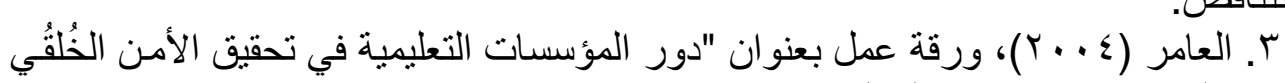

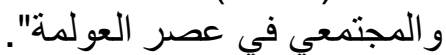

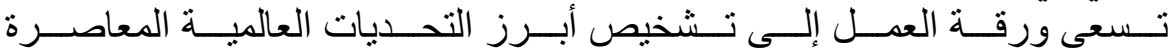

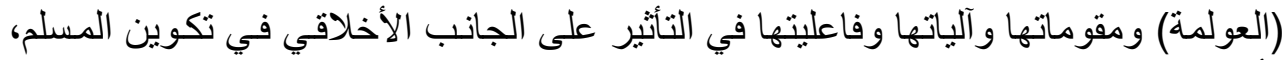

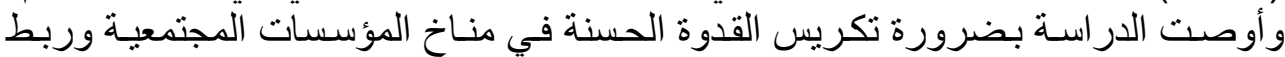

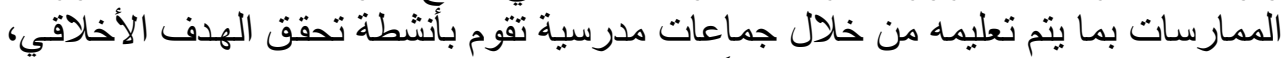

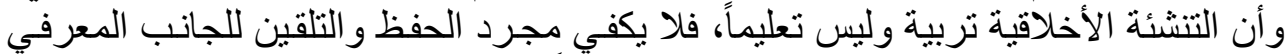

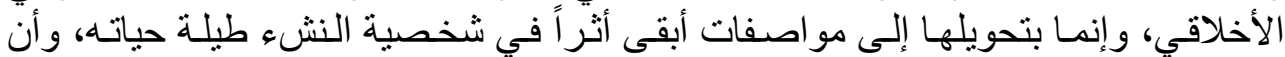

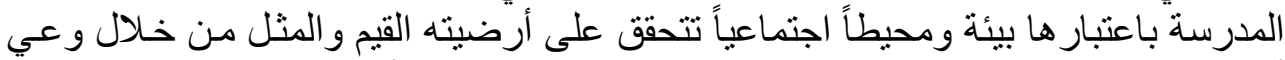

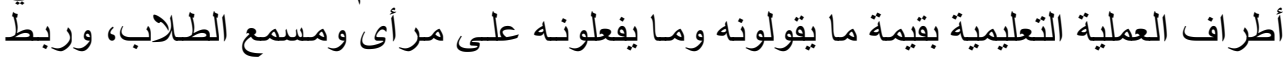




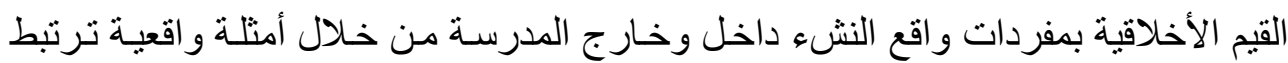

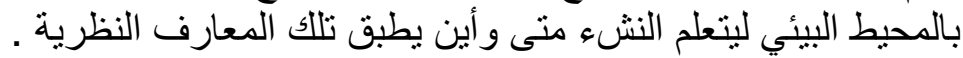

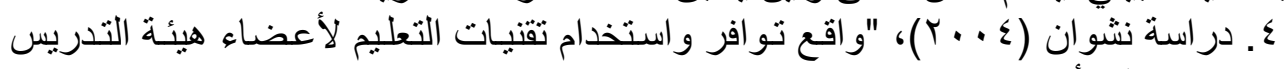

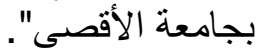
تناولت هذه الدر اسة واقع تو افر تقنيات التعليم لدى أعضاء هيئة التدريس و استخدامها من قبلهم في جامعة الأقصى. وقد أَعد لذلك قائمة بتقنيات التعليم اللازمة للتعليم الجامعي في شكل استبانة طبقة

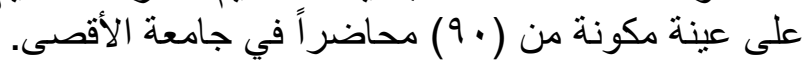

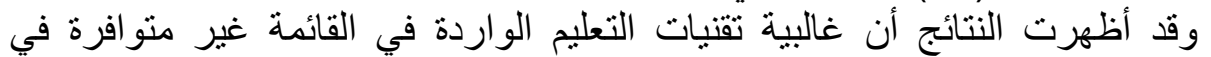

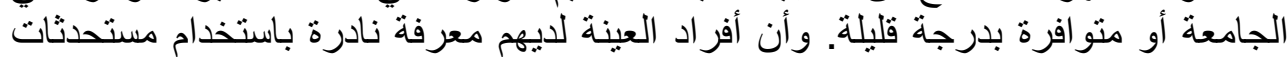

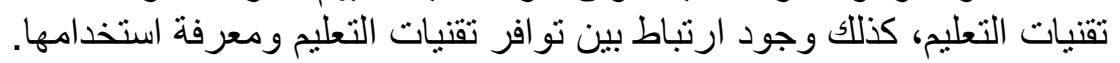

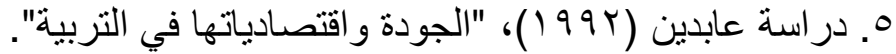

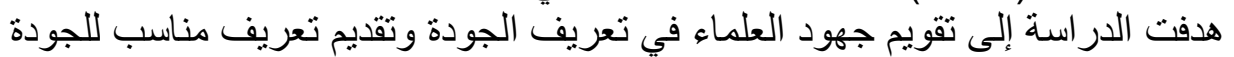

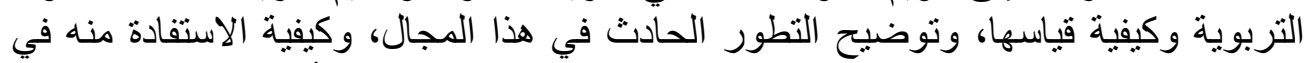

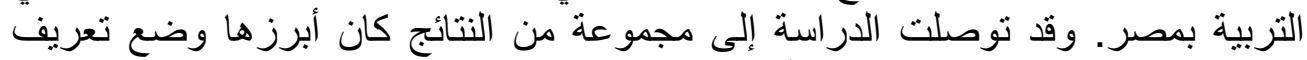

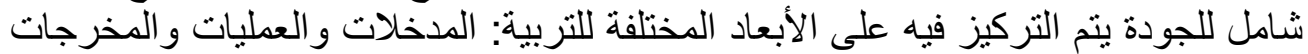

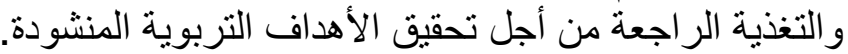

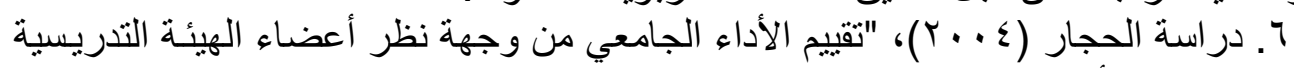

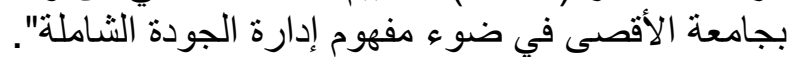

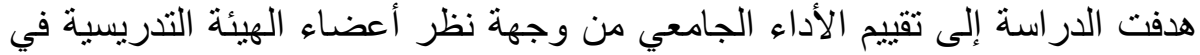

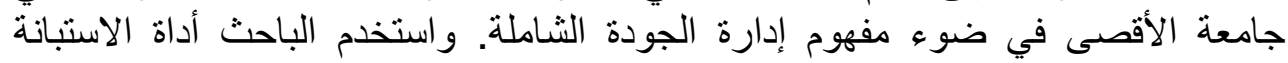

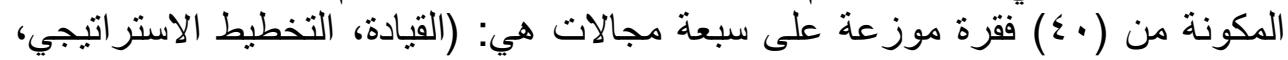

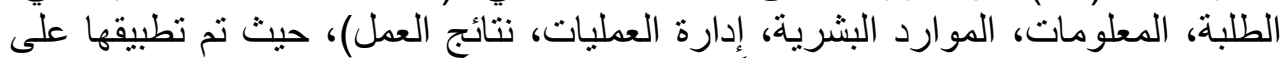

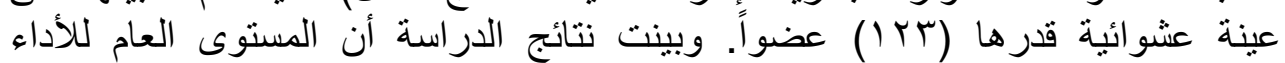

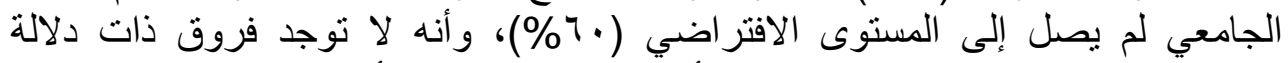

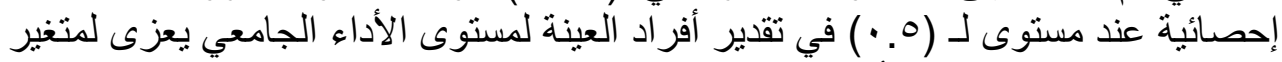

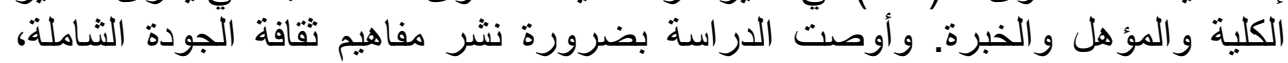

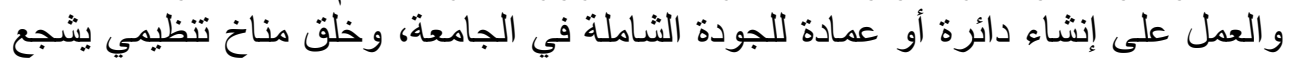
على الجودة الثاملة.

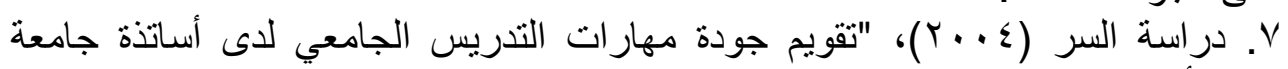
الأقصى في غزة".

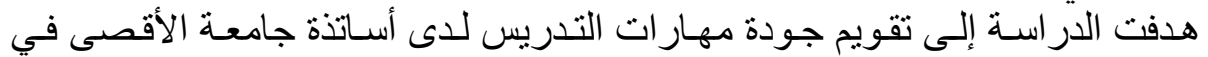

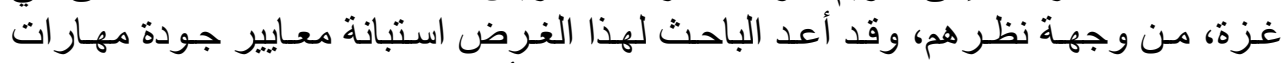

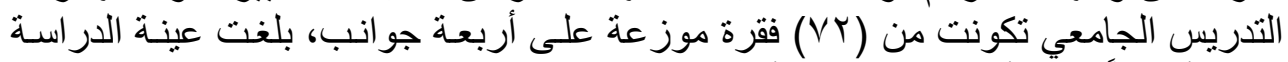

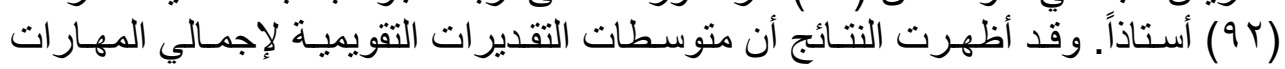

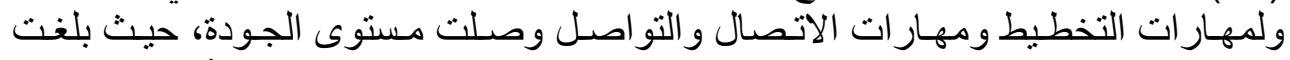

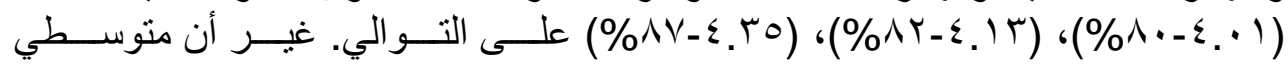

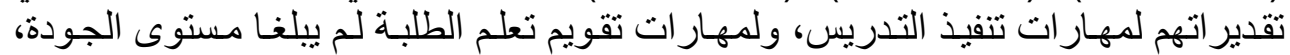

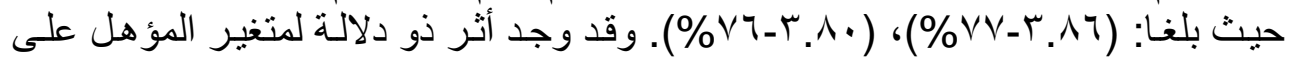




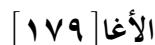

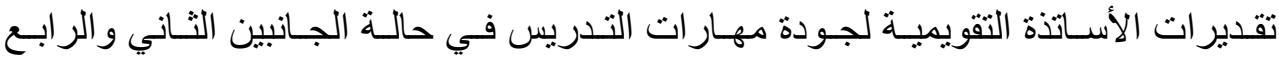
و إجمالي الجوانب، بينما لم يوجد ذللك الأثر لمتغيري الخبرة الخبرة والكلية.

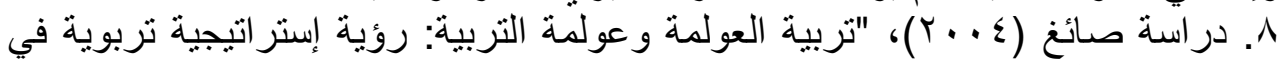

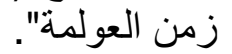

تناولت الدراسة علاقة العولمة بالتربية من خلال بعدي "تربية العولمة" و "عولمة

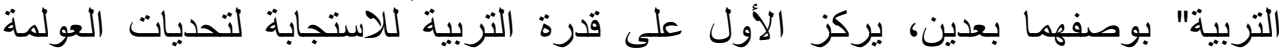

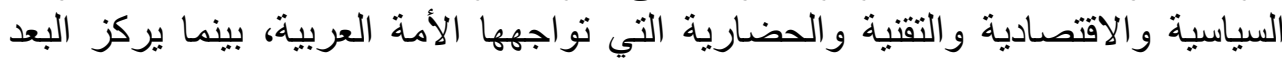

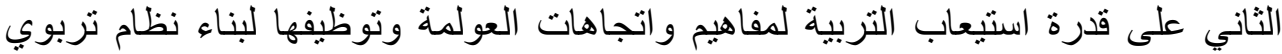
متطور يمتلك مقومات المرونة و المنافسة على الساحة الدولية. وتتضمن هذه الدراسة ستة عناصر رئيسية وهي: "التربية الخلفية، التربية الثورية

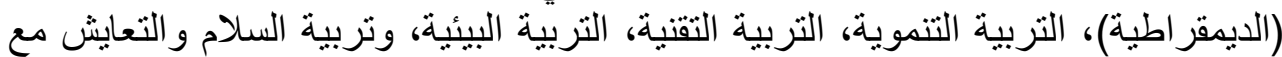

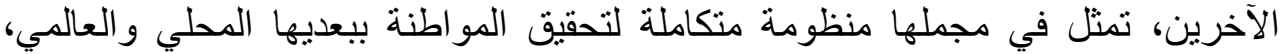
و القادرة على الإسهام في تحقيق " العولمة المتزنة".

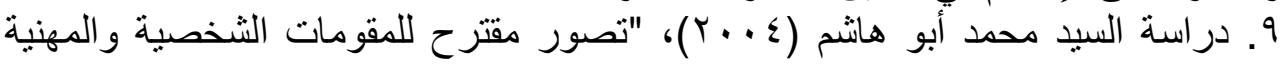

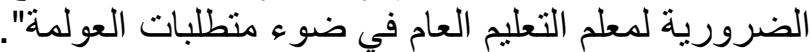

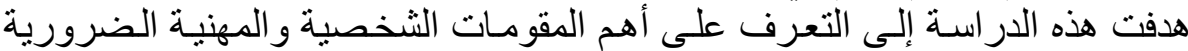
لمعلم التعليم العام في ضوء متطلبات العولمة. وذللك من خلال الإجابة عن عدد من الأل الأسئلة

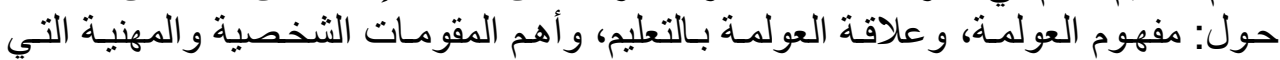

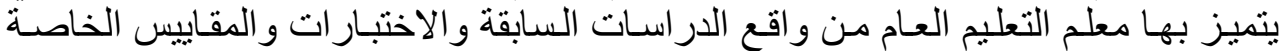

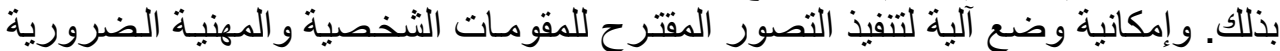

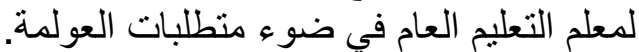

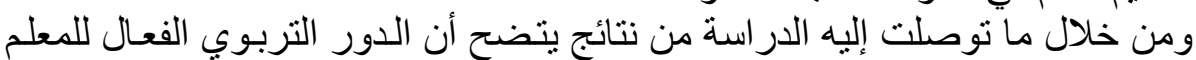

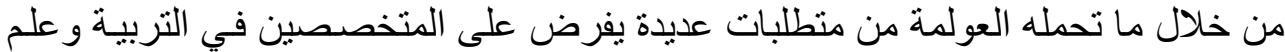

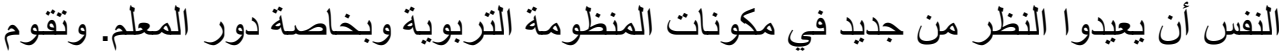

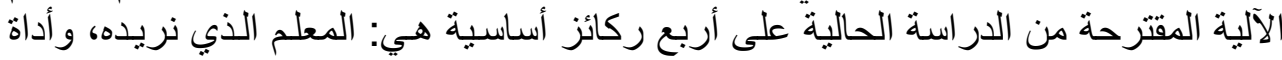
التطبيق، و الطريقة، و النتائج المتوقة التعة.

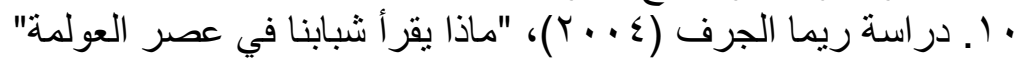

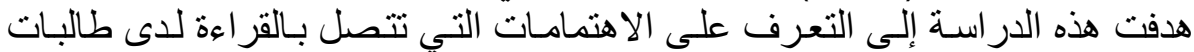

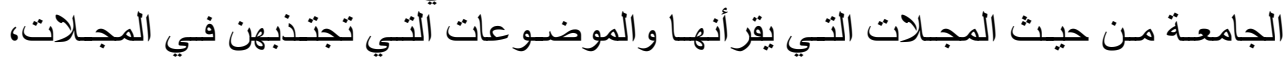

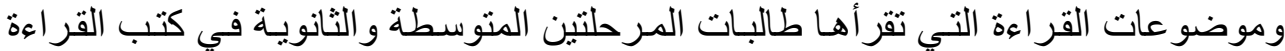

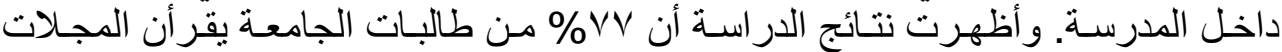

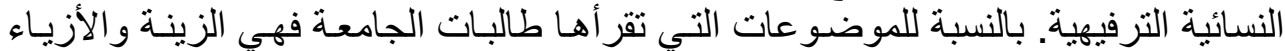
\%VV

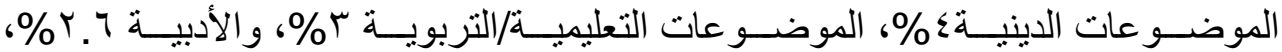

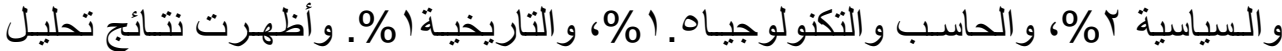

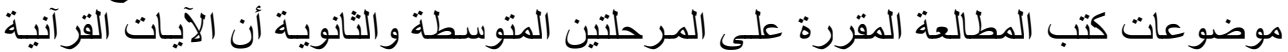

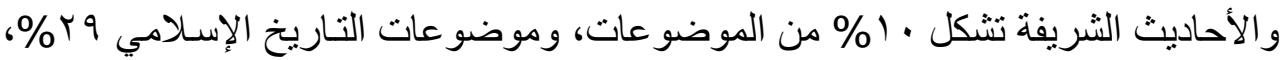

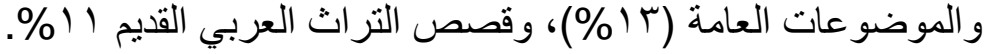




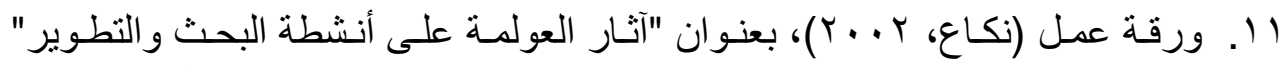

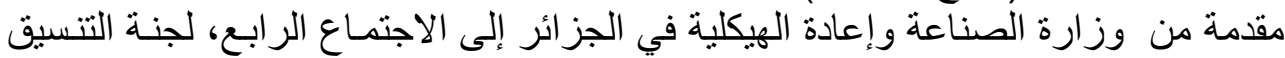

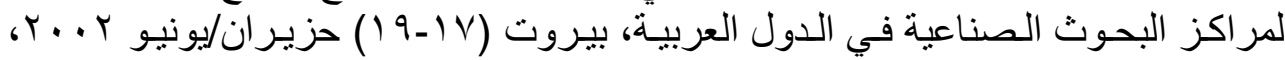

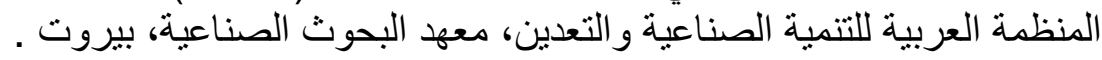

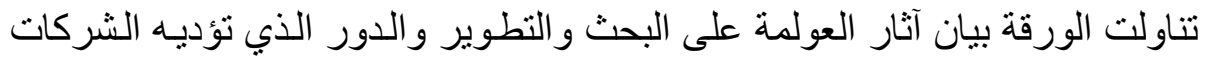

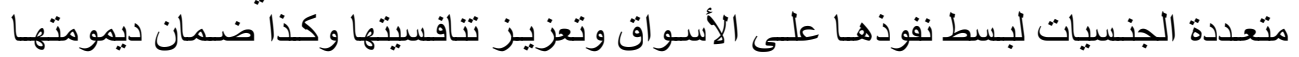

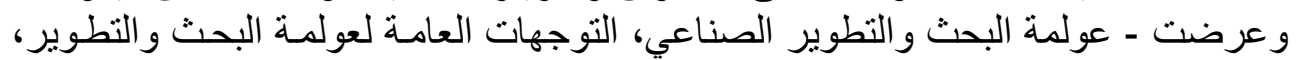

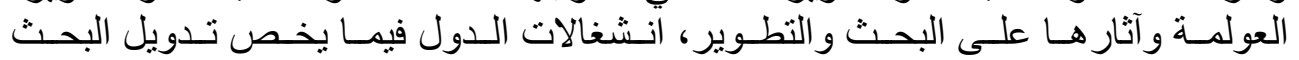

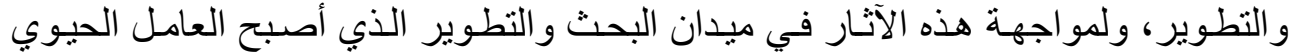
و المحرك الرئيس للتنافسية الدولية.

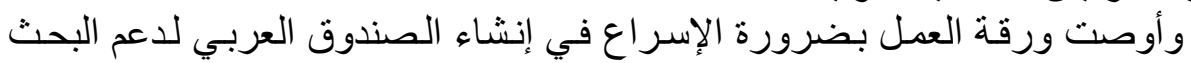

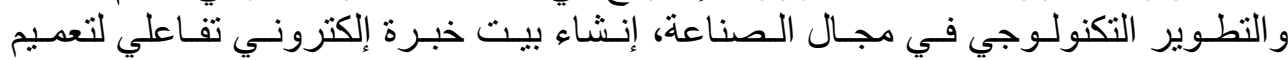

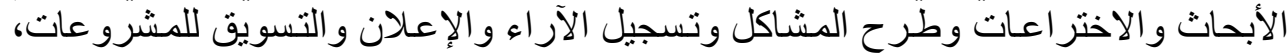

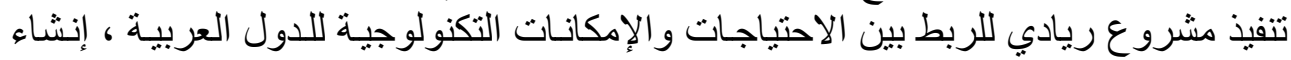

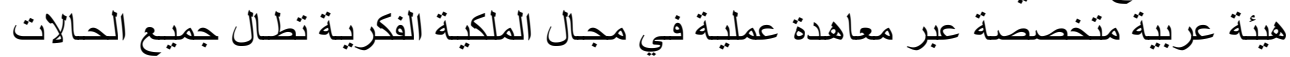
الإبداعية في الوطن العربي.

التعليق على الاراسات السابقة من خلال إطلاع الباحث على العى الدرابة اسات السابقة فقد تبين الآتي:

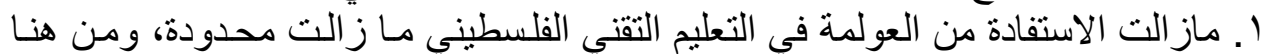

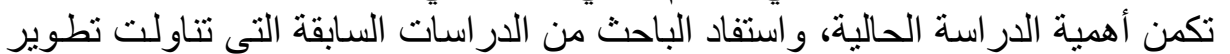

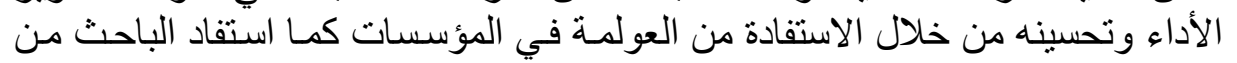

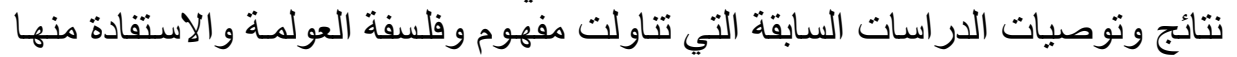

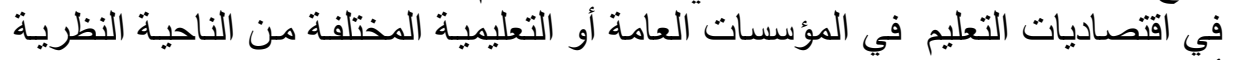

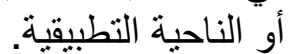
r. هدفت أغلب الدراسات إلى الكثفة عن أهمية التعرف على ما تتتجه العولمة من تطور

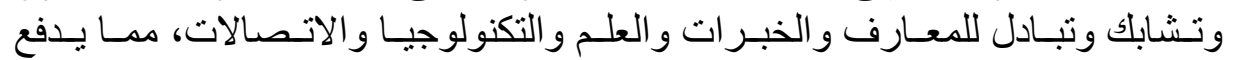

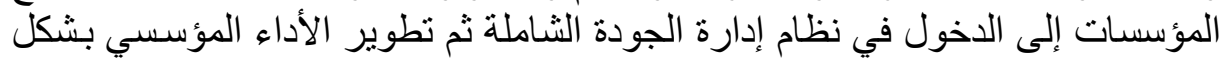

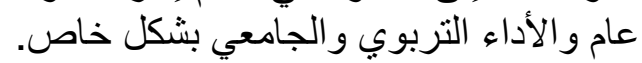

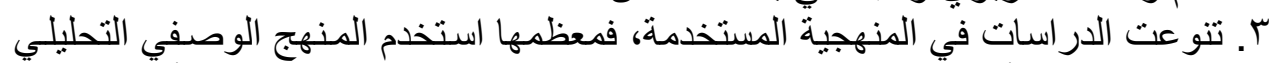

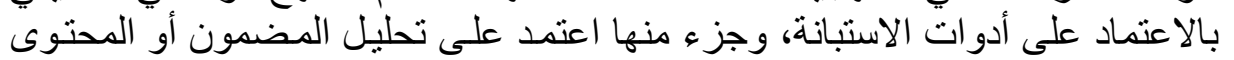
وتحليل المفاهيم.

أوجه الاتفاق والاختلاف والإفادة بين الدراسة الحالية والدراسات السابقة:

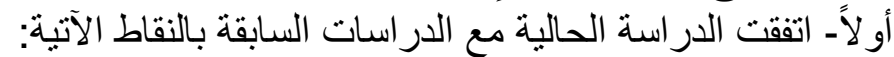

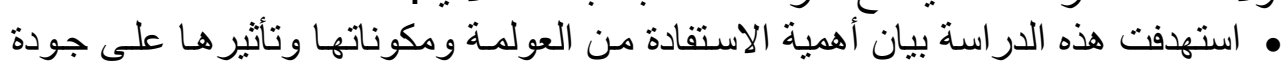

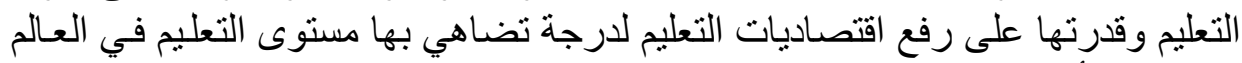

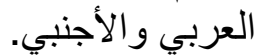




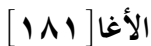

• التعرف إلى المعوقات التي تقف حائلاً أمسام الاستفادة مـن العولمـة في الارتقاء بمستوى التعليم التقني في فلسطين.

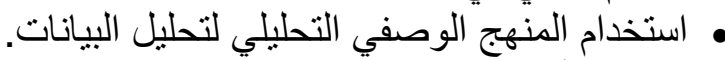
• • استخدام أدوات الدر اسة المتمثلة في الاستبانة. • الخروج بتوصيات تسهم في علآج القصور الذيتئة الذي توصل إليـه الباحث من واقع نتائج

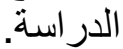

اختلفت الاراسة الحالية عن الاراسات السابقة في الآتي:

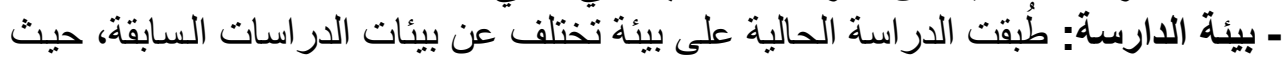

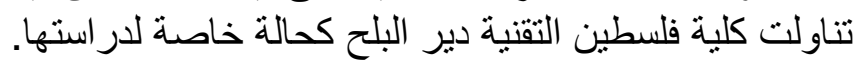

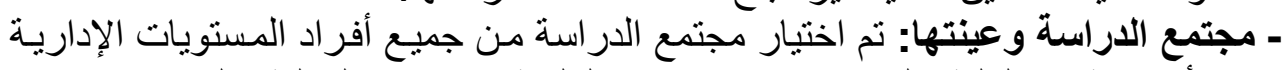

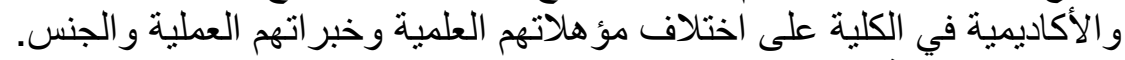

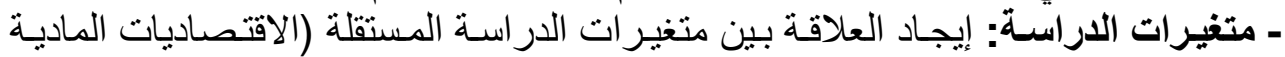

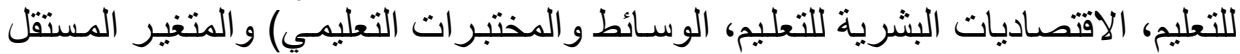

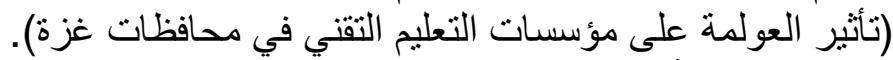

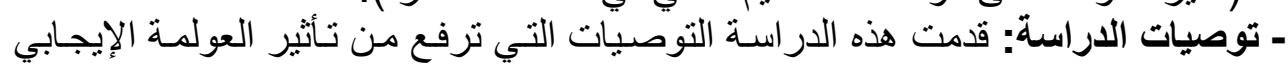
في تتمية اقتصاديات التعليم التقني.

طريقة وإجراءات الار استة

هدفت الدراسة إلى التعرف على التى علاقة العولمة بتنمية اقتصاديات التعليم في كلية فلسطين التقنية؟ ولتحقيق هذا الهذف سوف نتناول في هذا الفصل طريقة وإجر اءواء التهات البحث،

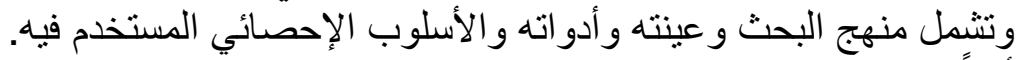
أولاً ـ منهج البحث البح

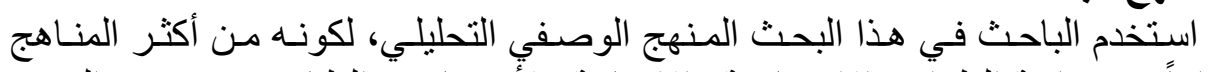

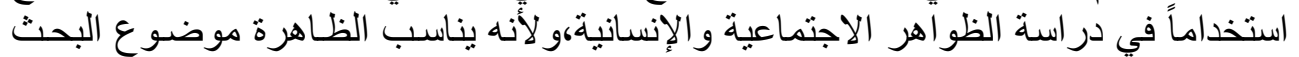

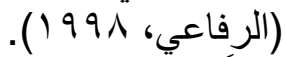

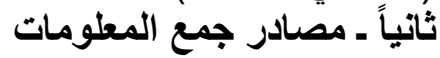

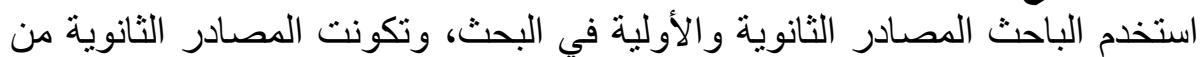

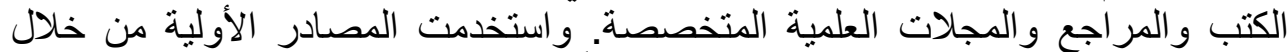

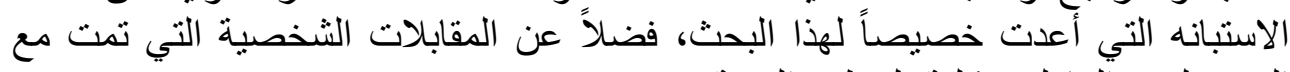
المسؤولين و الّعاملين بكلية فلسطين التقبت التقية.

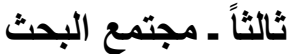
يتكون مجتمع البحث من جميع العـاملين المتفر غين بالكلية فلسطين التقنية وعددهم (1 1 (1) موظف.

\section{رابعاً ـ عينة البحث}

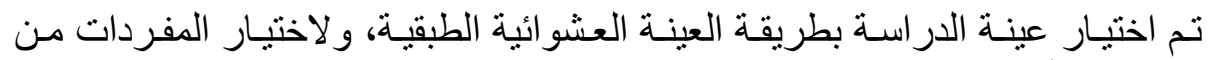
المجتمع الجزئي أو الطبقة تم استخدام طريقة التوزيع المتناسب (Proportional Allocation) بحيث تكون نسبة مفردات كل طبقة في العينـة مساوية لنسبة مفردات الطبقة في المجتمـع. 
وقد تم اختيار عينة الدراسة بحسب متغير ات الدراسـة، حيث بلغ عدد أفر اد العينة ( (ه)

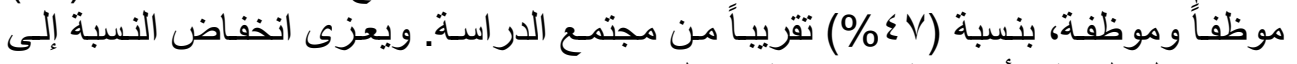
عدم تفاعل الهيئة الأكاديمية والإدارية مع الباحث.

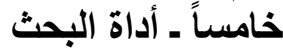

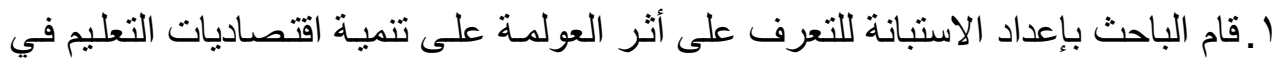

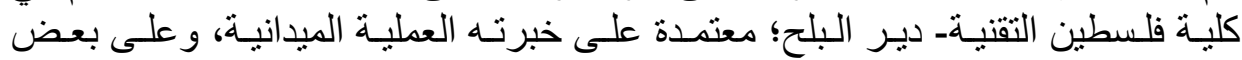

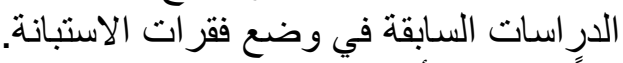

$$
\begin{aligned}
& \text { سادسا ـ صدق الأداة } \\
& \text { 1. إلدق المحكمين }
\end{aligned}
$$

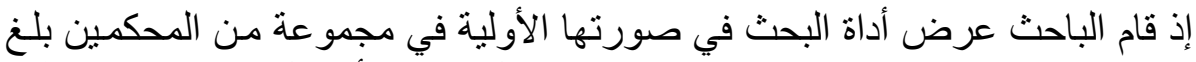

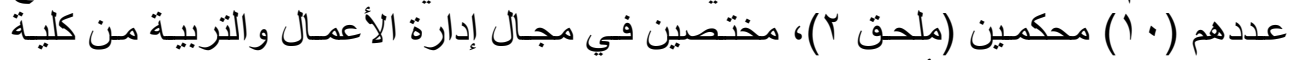

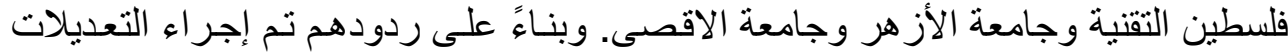

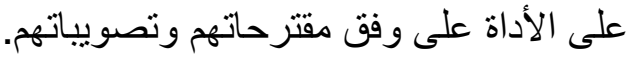

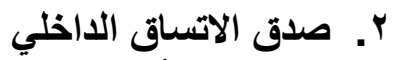

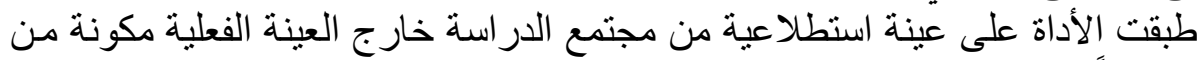

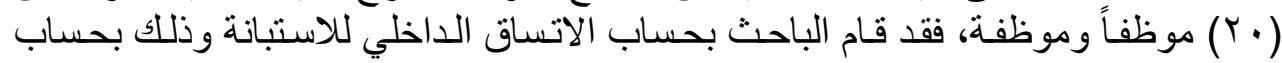

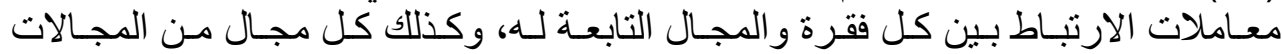
و المعدل الكلي لفقرات الاستبانة.

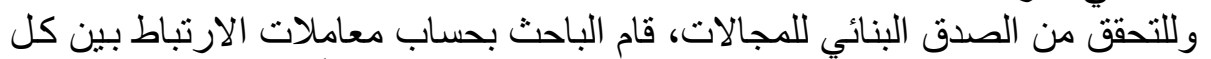

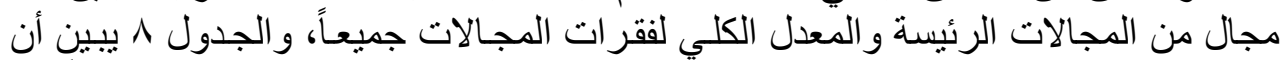

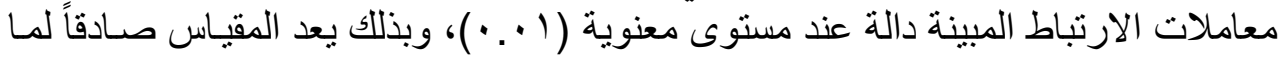

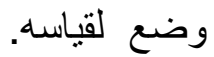

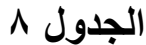

\begin{tabular}{|c|c|c|c|}
\hline مستوى الدلالة & معامل الارتباط & المجال & الرقم \\
\hline$\because \cdots$ & $\cdot . \wedge \varepsilon V$ & مجال الاقتصاديات المادية للتعليم & .1 \\
\hline$\because \cdots$ & $\cdot .947$ & مجال الاقتصاديات البشرية للتعليم & $\overline{. r}$ \\
\hline$\because \cdots$ & $\cdot . \mathrm{VTT}$ & مجال المختبر ات و الوسائط التعليمية &.${ }^{r}$ \\
\hline
\end{tabular}

معاملات الارتباط بين كل مجال و المعدل الكلي لفقرات الاستبانة

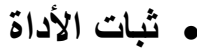

وقد اجرى الباحث خطوات الثبات على العينة الاستطلاعية نفسها بطريقتين هما طريقة التجزئة النصفية، ومعامل ألفا كرونباخ.

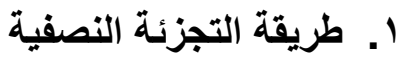

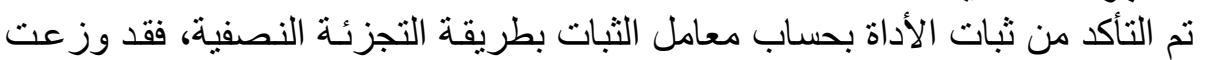

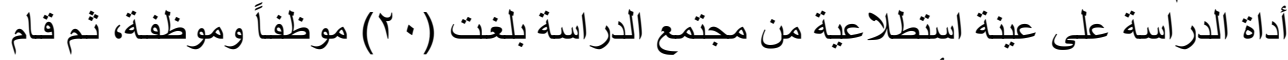

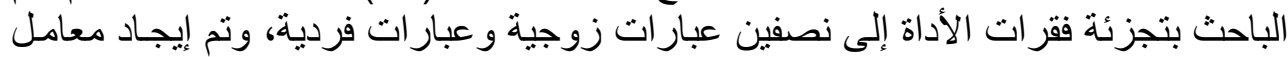




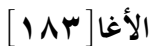

ارتبـاط بيرسـون بين معدل الأسئلة الفرديـة ومعدل الأسئلة الزوجيـة لكل مجـال، وقد تم تصحيح معاملات الارتباط باستخدام معامل ارتباط سبيرمان الفعدان للتصحيح.

\section{الجدول}

معاملات الارتباط بين معدل الفقرات الزوجية والفردية لكل مجال من المجالات الثلاثــة

\begin{tabular}{|c|c|c|c|c|c|}
\hline مستوى الدلاكة & معامل الارتباط & الارتباط & الفقرات & 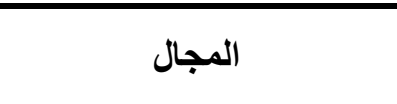 & 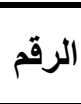 \\
\hline$\because \cdots$ & .940 & $\cdot .90 \leqslant$ & 7 & الاقتصـاديات المادية للتعليم & .1 \\
\hline$\because \cdots$ & $\because \vee \wedge \wedge$ & $\cdot .9 \leq 0$ & IT & الاقتصاديات البشرية للتعليم & $r$ \\
\hline$\because \cdots$ & $\cdot .9 \leqslant r$ & $\cdot .97 \mathrm{~V}$ & $\varepsilon$ & المختبر ات و الوسائط التعليمية & $r$ \\
\hline$\because \cdots$ & $\cdot . \wedge \wedge \wedge$ & .900 & Tr & فقر ات الأقسام جميعاً & \\
\hline
\end{tabular}

وقد تبين من الجدول 9 أن معاملات الارتباط ذات دالة احصائية عند مستوى دلالة $\therefore 0$

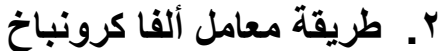

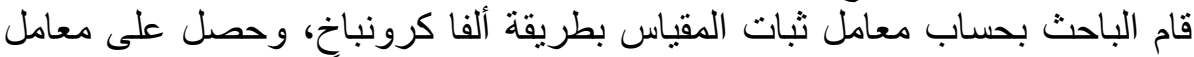

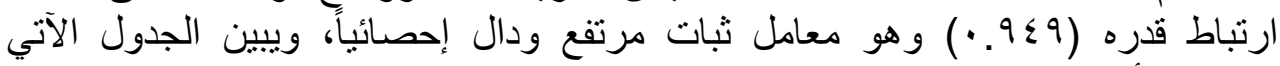

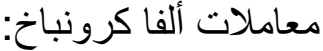

\begin{tabular}{|c|c|}
\hline عدد الفقرات & معامل ألفا كرونباخ \\
\hline YY & $9 \leqslant 9$ \\
\hline
\end{tabular}

$$
\text { ويبين الجدول · ـ معاملات "ألفا كرونباخ". }
$$

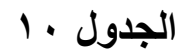

معاملات ألفا كرونباخ لفقرات الأستبانة

\begin{tabular}{|c|c|c|}
\hline معامل ألفا & معامل الارتباط & الفقزة \\
\hline \multicolumn{3}{|r|}{ مجال الاقتصاديات المادية للتعليم } \\
\hline $9 \leqslant 0$ & $V \varepsilon V$ & تؤثز العولمة في تحسين قاعات الدر اسة. \\
\hline $9 \leqslant V$ & .709 & ترفع العولمة من كفاءة مختبرات الدر اسة. \\
\hline $9 \leqslant 7$ & .791 & ترتبط سياسة تطوير مباني الكلية بالعولمة. \\
\hline $9 \leqslant 0$ &.$\vee 01$ & تعمل العولمة على تحسين المر افق العامة بالكلية. \\
\hline $9 \leqslant 0$ & $V Y T$ & تحسين مستوى ملاعب الكلية يرتبط بتطبيق العولمة. \\
\hline $9 \leqslant 7$ & 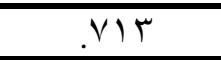 & تفيد العولمة في زيادة فرص تطوير مكتبة الكلية. \\
\hline \multicolumn{3}{|r|}{ مجال الاقتصاديات البشرية للتعليم } \\
\hline $9 \leqslant 9$ & $\leqslant 71$ & تتطبيق العولمين مستوى الكـادر الأكـاديمي في الكليـة يـرتبط \\
\hline $9 \leqslant 1$ & $\Sigma 9 V$ & تبذل الكلية جهوداً لتحسين الكادر الإداري في الكلية. \\
\hline
\end{tabular}




\begin{tabular}{|c|c|c|}
\hline معامل ألفا & معامل الارتباط & 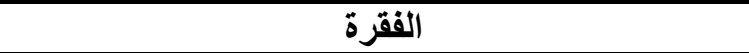 \\
\hline $9 \leqslant 7$ & $70 \leqslant$ & 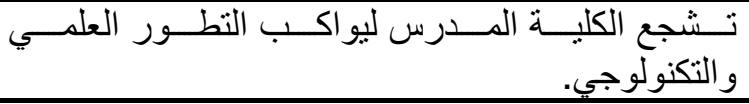 \\
\hline $.9 \leqslant V$ & $.09 \mathrm{~V}$ & أنتشنع الكليـة سياسـات أكثر مهنيـة وتخصـصية في أداء \\
\hline $9 \leqslant V$ & $.0 \wedge Y$ & الأكاديمي في الكليـة من الخبة. \\
\hline $9 \leqslant 1$ & .071 & تحفز الكلية الفنبين لمو اكبة التطور العلمي والتكنولوجي. \\
\hline $9 \leqslant 7$ & .791 & تطور الكلية من استر اتيجياتها لقيادة الكلية. \\
\hline $9 \leq 7$ & $v \cdots$ & تضينة الكلية استر اتيجيات بديلـة لقيادة الكلية في ظروف \\
\hline $9 \leqslant 7$ & .700 & تساعد العولمة إدارة الكلية في اتخاذ قرارات هامة. \\
\hline $9 \leqslant 7$ & $. V \leqslant r$ & في الكلية من خلال التلية من مهار ات التدريس لدى الكادر الأكاديمي \\
\hline $.9 \leq 7$ & VTo & سياســين مهار العمل المثبتة. التـدريب لـدى الفنيـين في الكليـة مـن \\
\hline $9 \leqslant 0$ & .177 & العولمة تخذم التوسع الأفقي للهيكل التنظيمي. \\
\hline & & مجال المختبرات والوسائط التعليمية \\
\hline $9 \leqslant 1$ & .079 & تستغل الكلية الوسائط البديلة المعينة على التدريس. \\
\hline $.9 \leq V$ & .091 & لمعايير الجودة الكلية على جعلية. مختبرات الكلية أكثر مواكبة \\
\hline $9 \leqslant 7$ & VYT & 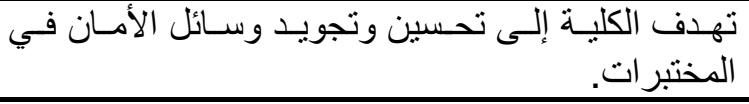 \\
\hline $9 \leqslant 0$ &.$\vee \neg \Lambda$ & 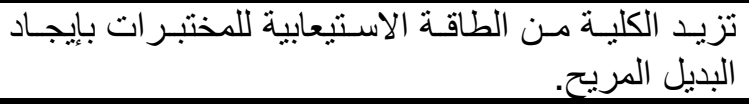 \\
\hline
\end{tabular}

\section{عرض النتائج ومناقشتها وتحليلها \\ سيتم عرض نتائج الدراسة ومناقتشنها على النحو الآتي:}

اختبار الفرضيـات

اـ الفرضية الأولى: تؤثر العولمة بشكل إيجابي في تنمية الاقتصاديات المادية للتعليم في

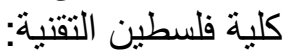




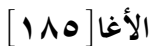

من أجل اختبار هذه الفرضية تم طرح ستة أسئلة على المبحوثين، للتعرف إلى مدى تأثير العولمة في تنمية الاقتصاديات المادية للتعليم في الكلية، و الجدول التالي يلية التين ذلك.

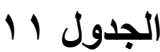

المتوسط الحسابي، والوزن النسبي والنسب المئوية لبدائل كل فقرة من فقرات المجال

الأول واختبار الإشارة للعينة الواحدة (Binomial Test):

\begin{tabular}{|c|c|c|c|c|c|c|c|c|c|c|}
\hline 青哥 & 高事 & 高示 & 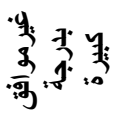 & *9. & 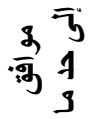 & के & 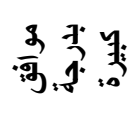 & 高 & فقرات المجال الأول & م. \\
\hline & $v \cdot .7$ & r.or & $\because$ & 0.9 & rV.r & $0 \leqslant .9$ & r. & 7 & تؤثر العولمة في تحسين قاعات & .1 \\
\hline$\because \ldots$ & vi.e & $r .00$ & $\because \cdot$ & 0.9 & $r V_{.} r$ & or. 9 & r.q & $\varepsilon$ & 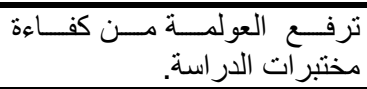 &.$r$ \\
\hline$\cdots$ & vi." & $r .00$ & $\because \cdot$ & 0.9 & $r q . r$ & $\leq 9$. & 0.9 & $\varepsilon$ & 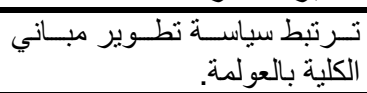 & $r$ \\
\hline & VY. & $r .71$ & $\because$ & r. 9 & $r 0 . r$ & 07.9 & r. .9 & $r$ & 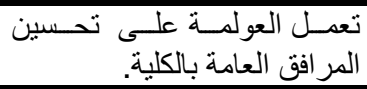 &.$\varepsilon$ \\
\hline & VY.T & r & . & 0.9 & rq. & 7.1 & r.q & r & تيرتبط بتطبين مستوى العولمة. & .0 \\
\hline & VT. & T.TV & $\because \cdot$ & r.. & ro.r & 07.9 & 0.9 & 1 & تطفيد العولمبة فلكيّة زيـادة فـرص & .7 \\
\hline$\because \cdots$ & $v 1.1$ & $r .011$ & & & & & 2II:" & & المعدل & \\
\hline
\end{tabular}

وفيما يأتي تفسير النتائج وفقاً لفقرات المجال الأول في الاستبانة: يتضح من الجدول السابق:

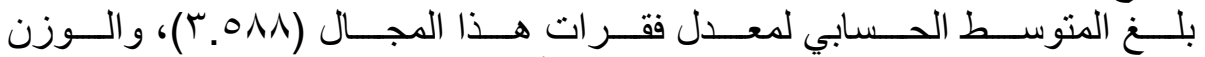

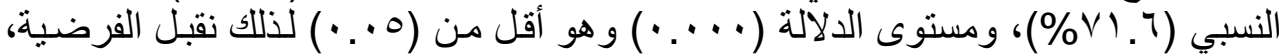

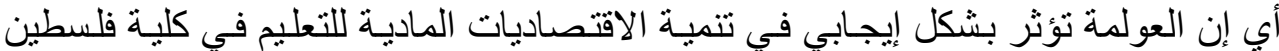

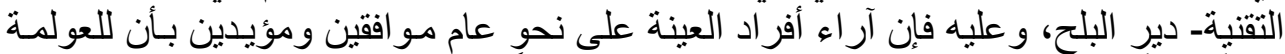

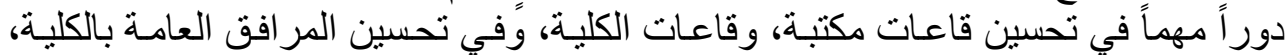
و أيضاً بمباني ومختبر ات وقين وقاعات كلية فلسطين التقنية. r. الفرضية الثانية: تؤثر العولمة بشكل إيجابي في تتمية الاقتصاديات البشرية للتعليم في كلية فلسطين التقنية:

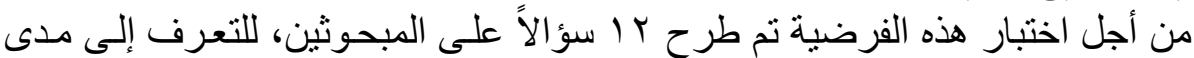

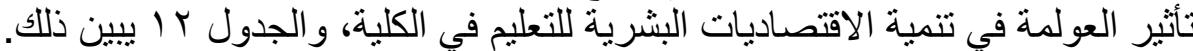

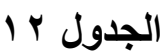

المتوسط الحسابي، والوزن النسبي والنسب المئوية لبدائل كل فقرة من فقرات المجال الثاني واختبار الإشارة للعينة الواحدة (Binomial Test): 


\begin{tabular}{|c|c|c|c|c|c|c|c|c|c|c|}
\hline 重牙 & 高量 & 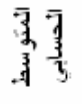 & $\frac{1}{3}$ & $\begin{array}{l}\frac{4}{2} \\
\frac{2}{3}\end{array}$ & $\begin{array}{l}\frac{2}{3} 4 \\
\overline{3} \\
=3\end{array}$ & $\frac{2}{\overline{3}}$ & 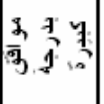 & 3 & فقُر اتَ الثُجال الثاني & ? \\
\hline$\cdots$ & 90,8 & $r, r v$ & $\because$ & $r_{1}$. & $x, 4$ & $r 0,0$ & $r_{1} \cdot$ & 15 & 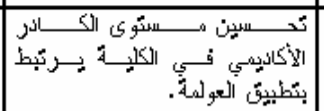 &.$y$ \\
\hline$\cdots$ & $90, \lambda$ & $r, r q$ & $\because$ & $r_{1} \cdot$ & $4 \lambda, 4$ & $r \vee, O$ & $\zeta_{1}$, & 11 & 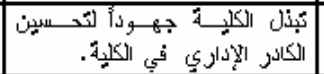 & $\lambda^{\lambda}$ \\
\hline$\cdots$ & $Y V_{1} \varepsilon$ & $r, r v$ & $\because$ & $r_{1}$. & $4, \lambda$ & $r o, r$ & $r_{1} \cdot$ & $\cdots$ & 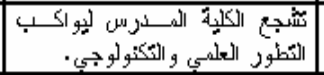 & $\begin{array}{l}.9 \\
\end{array}$ \\
\hline$\cdots$ & 49,0 & $r, \varepsilon o$ & $\because$ & $r_{1}$. & $o \mathfrak{q}, q$ & $r q, r$ & $r, q$ & q & 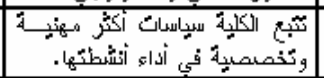 & $\pi$ \\
\hline$\cdots$ & $v 0,4$ & r,or & $\because$ & $r_{1}$. & $\left.\varepsilon v_{1}\right)$ & $\left\{v_{1}\right\}$ & $r, q$ & A & 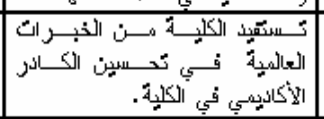 & .11 \\
\hline$\cdots$ & $\mathrm{VT}_{6}$, & $r, 40$ & $\because$ & $r_{1}$. & $r r, r$ & $4 Y, Y$ & $r_{1}$. & v & 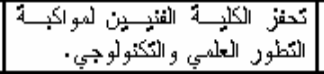 & .15 \\
\hline$\cdots$ & $\nabla Y, \lambda$ & $r, A \varepsilon$ & $\because$ & $r, q$ & $9, A$ & $\lambda \varepsilon, r^{\prime}$ & $r_{1} \cdot$ & $\mathfrak{\varepsilon}$ & 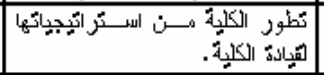 & $.1 \%$ \\
\hline$\cdots$ & $Y Y, \varepsilon$ & $r, A r$ & $\because$ & 0,9 & $\gamma, A$ & $\lambda \varepsilon, r$ & $r_{1}$. & 。 & 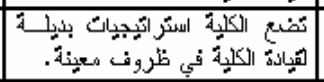 & \begin{tabular}{|l|}
.18 \\
\end{tabular} \\
\hline$\cdots$ & $v 4, v$ & $r, \lambda$, & $\because$ & 0,9 & $9, A$ & $\lambda r_{1} \varepsilon$ & $r_{1}$. & 4 & 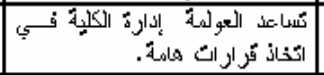 & .10 \\
\hline$\cdots$ & $\forall \lambda_{1} \cdot$ & $r, q$, & $\because$ & $r_{1}$. & $9, A$ & $\wedge \varepsilon, y^{r}$ & $r, q$ & r & 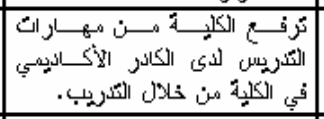 & \begin{tabular}{|l|}
.14 \\
\end{tabular} \\
\hline$\cdots$ & $\forall \mu_{1}$, & $r, q$, & $\because$ & $r, q$ & 0,9 & $\lambda 4,{ }^{r}$ & $r, q$ & r & 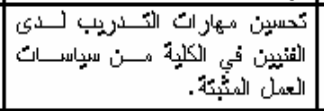 & $.1 \mathrm{~V}$ \\
\hline$\cdots$ & $\checkmark \wedge, \lambda$ & $r, q \varepsilon$ & $\because$ & $r, q$ & $r_{1}$ & 90,5 & $r, q$ & 1 & 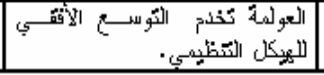 & $.1 A$ \\
\hline$\cdots$ & $\cdot . \mathrm{VY}^{\mathrm{T}}$ & $r, y \leqslant \AA$ & & & & & لرجا| & & & \\
\hline
\end{tabular}

وفيما يأتي تفسير النتائج وفقاً لفقرات الدجال الثاني في الاستبانة:

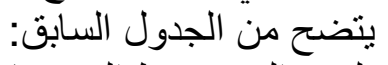

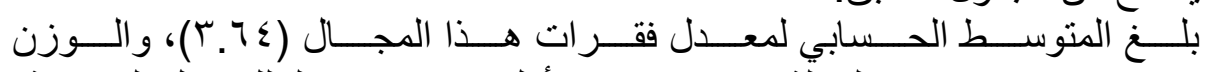

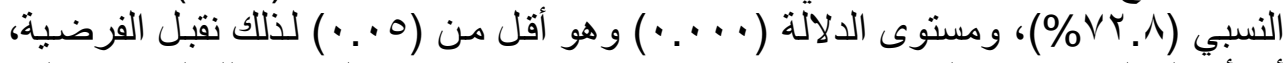

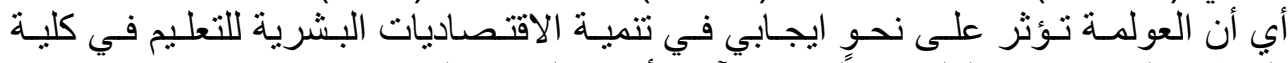

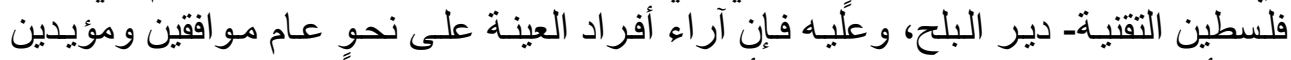

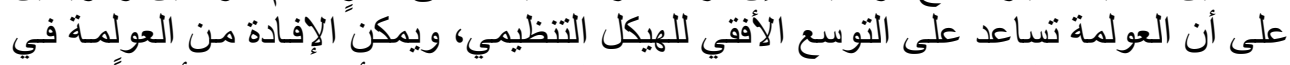

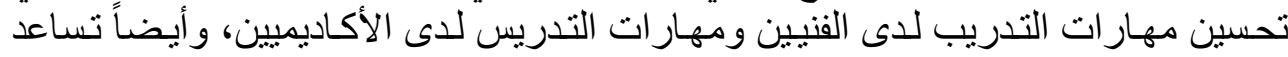

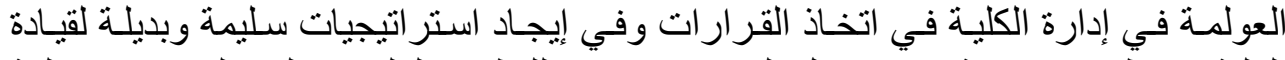
الكلية في ظروف معينة، وفي جعل الفنيين مواكبين للتطور العلدي و التكنولوجي في كلية فلسطين التقنية. r. الفرضية الثالثة: تؤثر العولمة على نحوٍ ايجابي في الإمكانيات التكنولوجية للتعليم في كلية فلسطين التقنية:

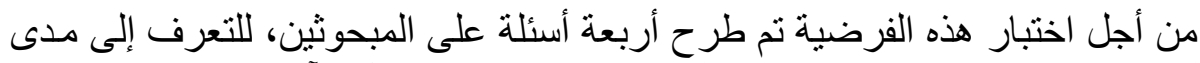

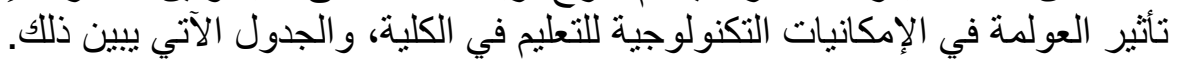




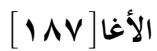

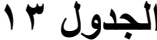

المتوسط الحسابي، والوزن النسبي والنسب المئوية لبدائل كل فقرة من فقرات المجال الثالث واختبار الإثشارة للعينة الواحدة (Binomial Test):

\begin{tabular}{|c|c|c|c|c|c|c|c|c|c|c|}
\hline 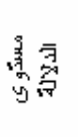 & 䒺哥 & 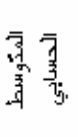 & 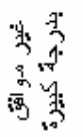 & 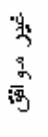 & $\begin{array}{l}\sum_{3}^{2} 1 \\
i_{3}^{3}\end{array}$ & 高 & 梦 & 亨 & ققرات المجل الثالث & ק \\
\hline$\cdots$ & vo, & r.vo & $\because$ & $\zeta_{1}$, & $\zeta 0,0$ & $Y \lambda, y$ & $\Upsilon \%, q$ & \{ & 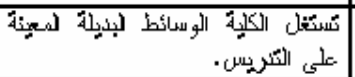 & .19 \\
\hline$\cdots$ & Yo, $Y$ & $r, \vee \lambda$ & $\because$ & $\zeta_{1}$, & $\lceil 1, \gamma$ & $\vee ५, 0$ & $r, q$ & $r$ & 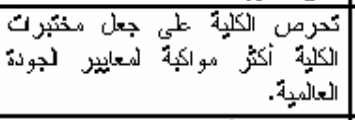 &.$r$ \\
\hline$\cdots$ & $W_{1}, r_{1}$ & $r, \lambda Y$ & $\because$ & $\zeta_{1} \cdot$ & $M r_{1}$ & $\lambda \cdot, \varepsilon$ & $r, 9$ & 1 & 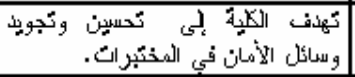 & .51 \\
\hline$\cdots$ & $\nabla 4, \lambda$ & $r, \wedge \leqslant$ & $\because$ & $\zeta_{1}$, & $M, Y$ & $\lambda r_{1} \varepsilon$ & $\zeta_{1} \cdot$ & $\zeta$ & 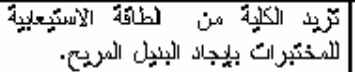 & TY \\
\hline$\because \cdots$ & $v y_{1}, v$ & $r, \lambda, \lambda$ & & & & & الثمجال & & أمعلز & \\
\hline
\end{tabular}

وفيما ياتي تفسير النتائج وفقاً لفقرات الججال الثالث في الاستبانة:

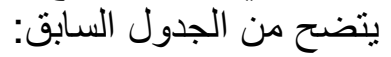

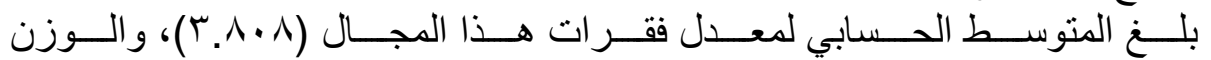

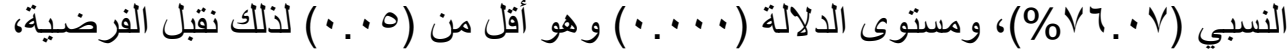

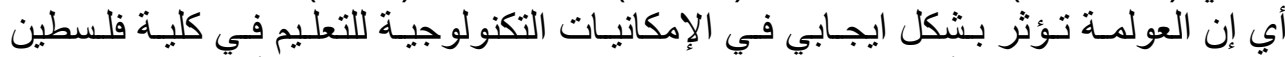

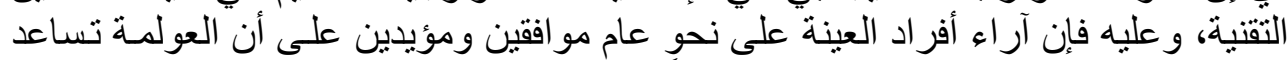

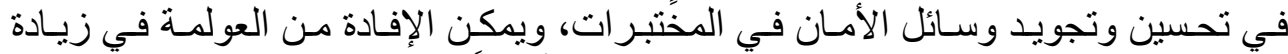

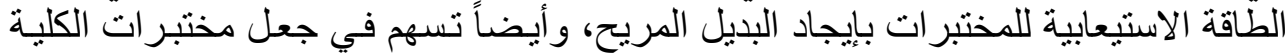
أكثر مواكبة لمعايير الجودة العالمية.

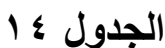

المتوسطات الحسابية، الأوزان النسبية ونتائج اختبار الإثارة لكل مجال ولمعدل فقرات الاستبانة جميعاً:

\begin{tabular}{|c|c|c|c|c|c|c|}
\hline مستوي & المئوية & الحستابي & 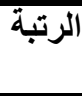 & الفقرات & المجال & 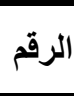 \\
\hline$\cdot, \cdots$ & VI.A. & r.ONAY & $\Gamma$ & 7 & مجال الاقتصاديات المادية للتعليم & 1 \\
\hline$\because \cdots$ & $\frac{V r}{V T}$ & $r . T \leqslant \lambda V$ & $\bar{r}$ & $\overline{T r}$ & مجال الاقتصاديات البشرية للتعليم & 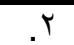 \\
\hline$\because \cdots$ & $V 7 . \cdot V$ & $\Gamma . \wedge \cdot \wedge \Lambda$ & $T$ & $\varepsilon$ & مجال المختبرات و الوسائط التعليمية & $r$ \\
\hline$\because \cdots$ & $\frac{V T . T}{T}$ & $r .7119$ & - & $\overline{T Y}$ & معدل فقرات الاستبانة جميعاً & \\
\hline
\end{tabular}

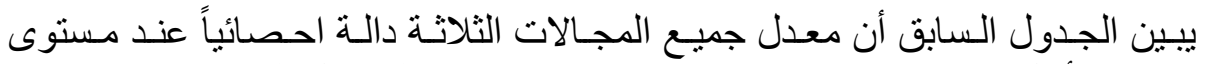

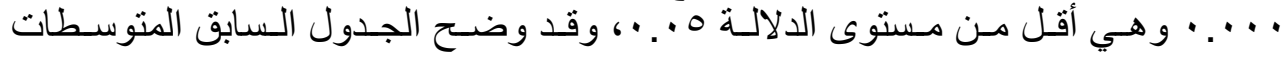




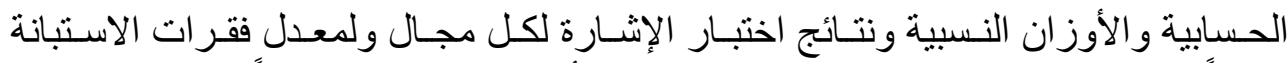

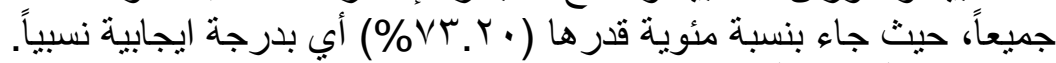

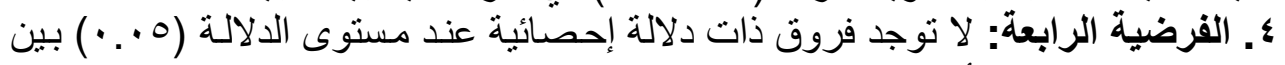

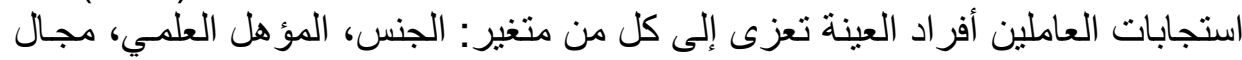
العمل، وسنوات الخبرة، بالنسبة لمجالات الاتينة الاستبانة الثناثة.

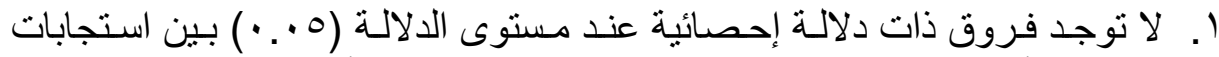

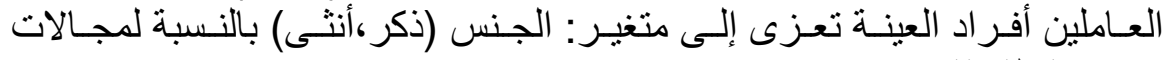
الاستبانة الثلاثة.

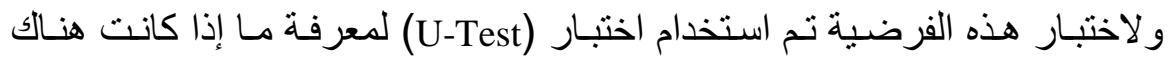

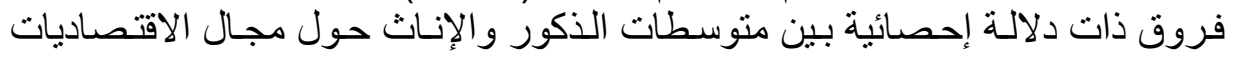

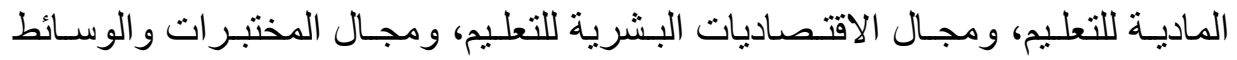

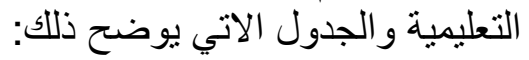

\section{الجدول مالمعز 10}

تحليل مان وتني (U-Test) لكل مجال ولمعدل الفقرات جميعاً بحسب متغير الجنس عند

\begin{tabular}{|c|c|c|c|c|c|}
\hline مستوي الدلاكي & 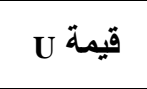 & متوسط الرتب & الجنس & 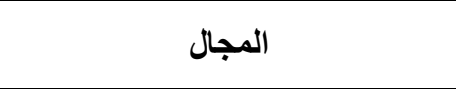 & 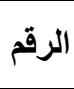 \\
\hline \multirow{2}{*}{ תוז. } & \multirow{2}{*}{ r) $1.0 \ldots$} & $r v .10$ & ذكر & \multirow{2}{*}{ مجال الاقتصاديات المادية للتعليم } & \multirow{2}{*}{.1} \\
\hline & & Tr.9T & أنثى & & \\
\hline \multirow{2}{*}{$\cdot .17$} & \multirow{2}{*}{ rir.... } & TV.YV & ذكر & \multirow{2}{*}{ مجال الاقتصاديات البشرية للتعليم } & \multirow{2}{*}{.$r$} \\
\hline & & TY.TE & أنثى & & \\
\hline \multirow{2}{*}{$\cdot \wedge \cdot \varepsilon$} & \multirow{2}{*}{$r \leq q . \ldots$} & YO.VT & ذكر & \multirow{2}{*}{ مجال المختبر ات و الوسائط التعليمية } & \multirow{2}{*}{ r } \\
\hline & & YT.VI & أنثى & & \\
\hline \multirow[t]{2}{*}{$\because \varepsilon \vee \wedge$} & \multirow{2}{*}{ rro.0.. } & $r 7.91$ & ذكر & \multirow{2}{*}{ معدل فقر ات الاستبانة جميعاً } & \\
\hline & & (T).T & أنثى & & \\
\hline
\end{tabular}

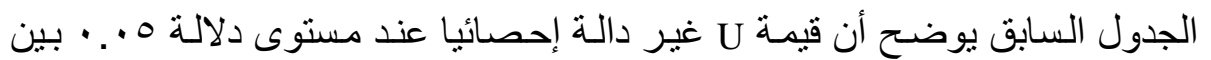

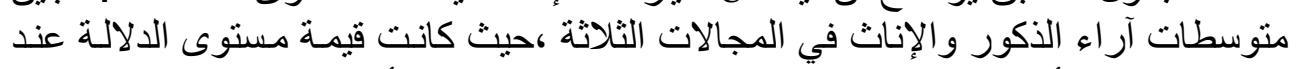

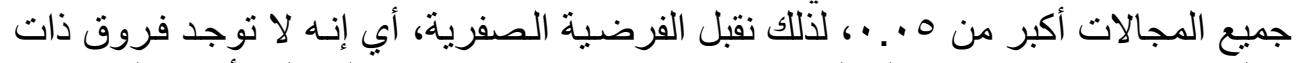

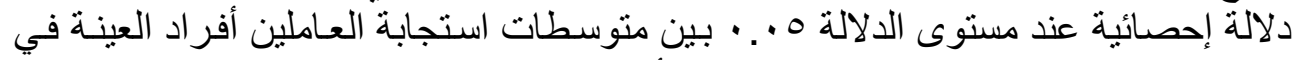
كلية فلسطين التقنية تعزى إلى الجنس البنس (ذكر ، أنثى).

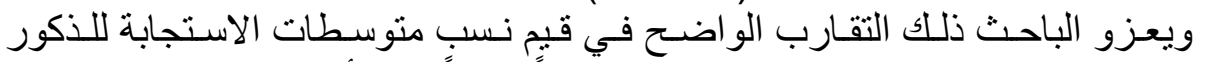

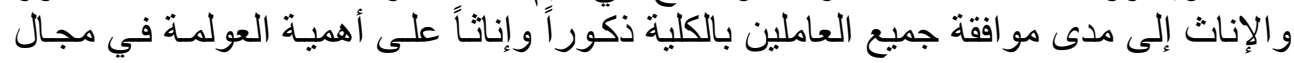

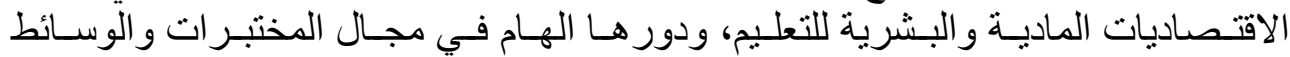
r. لا توجد فروق ذات دلالة إحصائية عند مستوى الدلالة (0 . . • ) بين استجابات العاملين

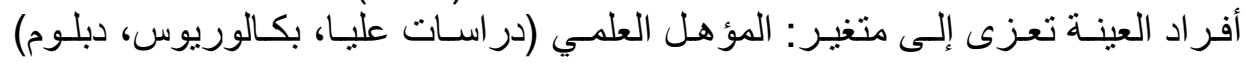




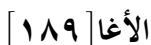

و لاختبار هذه الفرضية تم استخدام اختبار (H-Test) لمعرفة ما إذا كانت هنالك فروق المباد

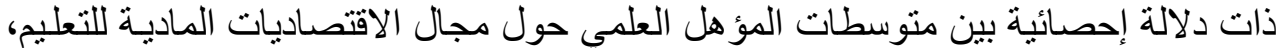

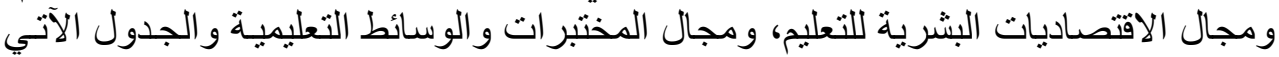

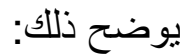

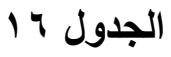

جدول كروسكال - والس (H-Test) لكل مجال ولمعدل الفقرات جميعاً بحسب متغير

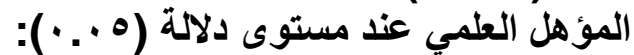

\begin{tabular}{|c|c|c|c|c|c|}
\hline مستوى الدلاكة & X & متوسط الرتب & المؤهل العلمي & 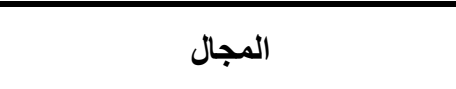 & 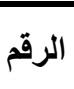 \\
\hline \multirow{3}{*}{$\cdot . \wedge \vee$} & \multirow{3}{*}{$1 . \leqslant \leqslant 1$} & r^.9) & در اسات عليا & \multirow{3}{*}{ مجال الاقتصاديات المادية للتعليم } & \multirow{3}{*}{.1} \\
\hline & & YY. $\leqslant 0$ & بكالوريوس & & \\
\hline & & YI. $\leqslant 0$ & | & & \\
\hline \multirow{3}{*}{$\cdot .94$} & \multirow{3}{*}{. .171} & TV.rT & در اسات عليا & \multirow{3}{*}{ مجال الاقتصاديات البشرية للتعليم } & \multirow{3}{*}{.$r$} \\
\hline & & Yo.9Y & بكالوريوس & & \\
\hline & & rE.Vo & د دبلوم & & \\
\hline \multirow{3}{*}{$\because .97$} & \multirow{3}{*}{$\varepsilon .7 \wedge v$} & r. T.00 & در اسات عليا & \multirow{3}{*}{ مجال المختبر ات و الوسائط التعليمية } & \multirow{3}{*}{$r$} \\
\hline & & $r r . A$ & بكالوريوس & & \\
\hline & & $T V .00$ & دبلوم & & \\
\hline \multirow{3}{*}{ ( } & \multirow{3}{*}{$.91 \%$} & Y9.71 & در اسات عليا & \multirow{3}{*}{ معدل فقرات الاستبانة جميعاً } & \\
\hline & & YO.YA & بكالوريوس & & \\
\hline & & $r \varepsilon .1$. & 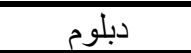 & & \\
\hline
\end{tabular}

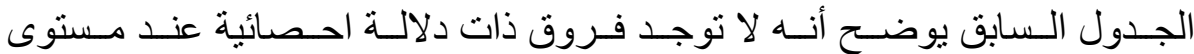

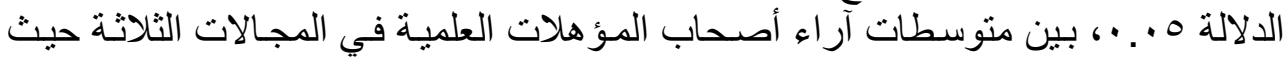

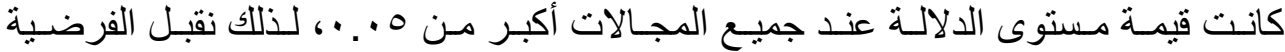

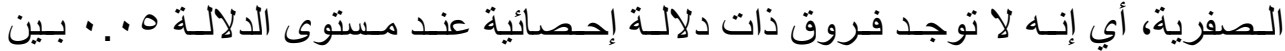

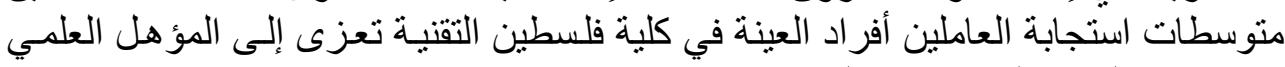

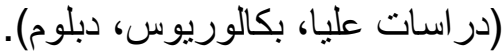
ويعزو الباحث ذلك التقـارب الو اضـح في قيم نسب متوسطات الاستجابة للمؤهل

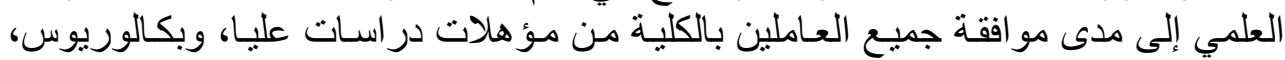

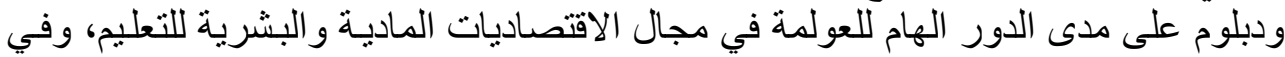
مجال المختبر ات و والوسائط التعليمية.

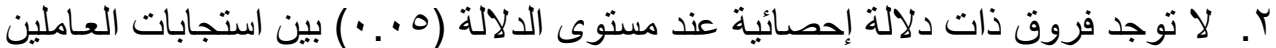

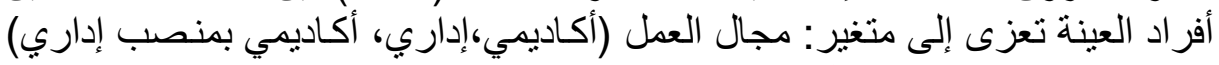
بالنسبة لمجالات الاستبانة الثناثة: ولاختبار هذه الفرضية تم استخدام اختبار (H-Test) لمعرفة ما إذا كانت هنالك فروق التانة

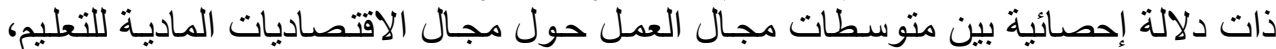


ومجال الاقتصاديات البشرية للتعليم، ومجال المختبرات و الوسائط التعليمية و الجدول الآتي يوضح ذلك:

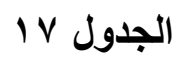

جدول كروسكال - والس (H-Test) لكل مجال ولمعدل الفقرات جميعاً بحسب متغير مجال

\begin{tabular}{|c|c|c|c|c|c|}
\hline مستوي & قيمة & متوسط الرتب & 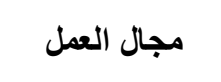 & 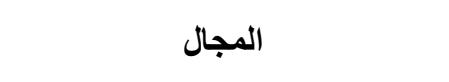 & 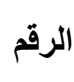 \\
\hline \multirow{3}{*}{$.6 \leqslant r \wedge$} & \multirow{3}{*}{1.799} & r..rq & أكاديمي & \multirow{3}{*}{ مجال الاقتصاديات المادية للتعليم } & \multirow{3}{*}{.1} \\
\hline & & $r \leq .1 T$ & إداري & & \\
\hline & & 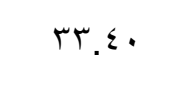 & أكاديمي بمنصب & & \\
\hline \multirow{3}{*}{.019} & \multirow{3}{*}{1.09} & ro. .9 & أكاديمي & \multirow{3}{*}{ مجال الاقتصاديات البشرية للتعليم } & \multirow{3}{*}{.$r$} \\
\hline & & ro.0. & 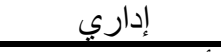 & & \\
\hline & & Tr.\&. & أكاديمي بمنصب & & \\
\hline \multirow{3}{*}{$\cdot .9 \cdot \varepsilon$} & \multirow{3}{*}{$\cdot r \cdot 1$} & r૫.V. & 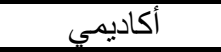 & \multirow{3}{*}{ مجال المختبر ات و الوسائط التعليمية } & \multirow{3}{*}{ r } \\
\hline & & YO.VY & 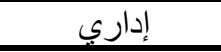 & & \\
\hline & & $r \leq .$. & أكاديمي بمنصب & & \\
\hline \multirow{3}{*}{.017} & \multirow{3}{*}{$1 . v \cdot$} & ro. $\leqslant r$ & أكاديمي & \multirow{3}{*}{\multicolumn{2}{|c|}{ معدل فقرات الاستبانة جميعاً }} \\
\hline & & ro. IV & إداري & & \\
\hline & & r. & أكاديمي بمنصب إداري & & \\
\hline
\end{tabular}

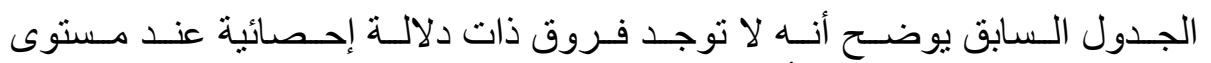

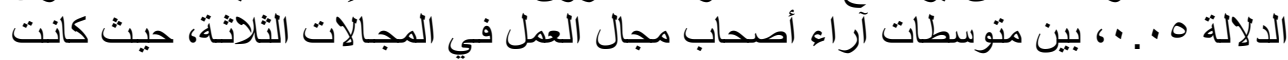

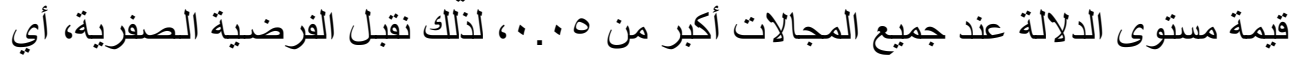

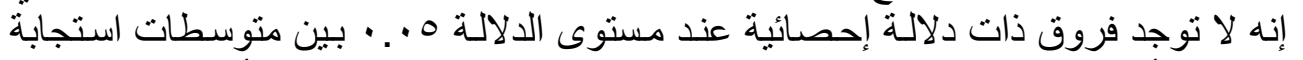

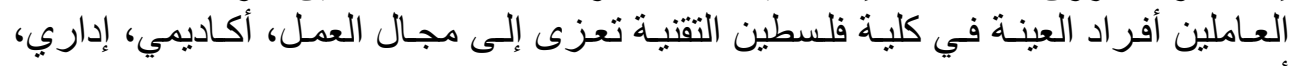

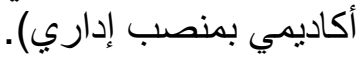

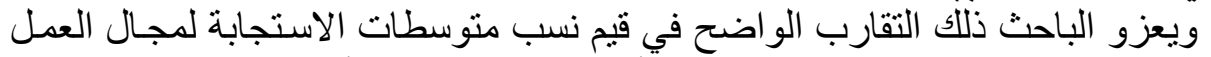

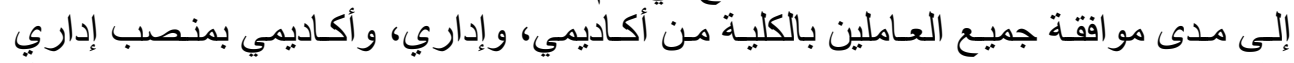

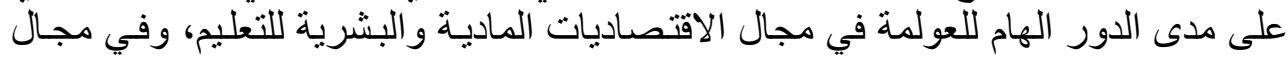
المختبر ات و الوسائط التعليمية. ع. لا توجد فروق ذات دلالة إحصائية عند مستوى الدلالة (0 . . • ) بين استجابات العاملين

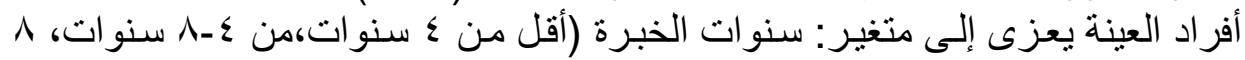
سنوات فأعلى) بالنسبة لمجالات الاستبانة الثلاثة:

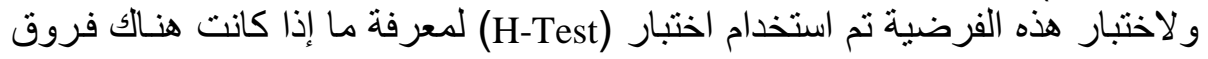

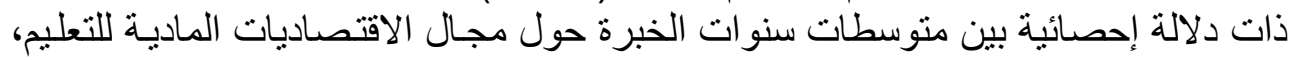




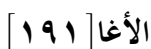

ومجال الاقتصـاديات البشرية للتعليم، ومجال المختبر ات والوسـائط التعليميـة والجدول الآتي يوضح ذللك:

\begin{tabular}{|c|c|c|c|c|c|}
\hline \multicolumn{6}{|c|}{ 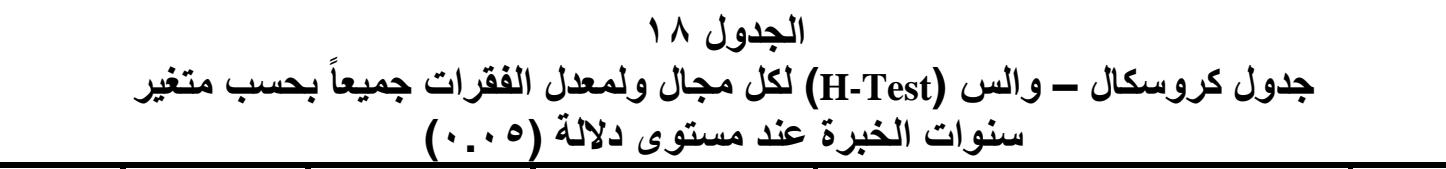 } \\
\hline مستولة & قيمة & متوسط الرتب & 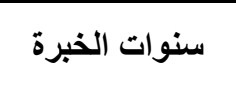 & 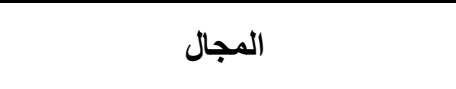 & الرقم \\
\hline \multirow{3}{*}{$\because .11$} & \multirow{3}{*}{$\wedge .99 \wedge$} & 10.74 & أقل من ₹ سنوات & \multirow{3}{*}{ مجال الاقتصاديات المادية للتعليم } & \multirow{3}{*}{.1} \\
\hline & & YA.0. & من ؟ -1 سنوات & & \\
\hline & & $r \cdot . r T$ & ^ سنوات فأعلى & & \\
\hline \multirow{3}{*}{. .109} & \multirow{3}{*}{$r .7 \wedge \varepsilon$} & 19.41 & أقل من ـ سنوات & \multirow{3}{*}{ مجال الاقتصاديات البشرية للتعليم } & \multirow{3}{*}{$r$} \\
\hline & & $r 9.4$ & من ع -1 سنوات & & \\
\hline & & rV.VO & ᄉ سنوات فأعلى & & \\
\hline \multirow{3}{*}{.$r 4$. } & \multirow{3}{*}{$r .797$} & $r \leqslant .70$ & أقل من گ سنوات & \multirow{3}{*}{ مجال المختبر ات والوسائط التعليمية } & \multirow{3}{*}{$r$} \\
\hline & & YY.TT & من ؟ - م سنوات & & \\
\hline & & rq.rT & ᄉ سنوات فأعلى & & \\
\hline \multirow{3}{*}{$\because \cdot r_{0}$} & \multirow{3}{*}{ V.rot } & 17.70 & أقل من ؟ سنوات & \multirow{3}{*}{ معدل فقرات الاستبانة جميعاً } & \\
\hline & & TV.rA & من ع -1 سنوات & & \\
\hline & & $r \cdot .0 r$ & ᄉ سنوات فأعلى & & \\
\hline
\end{tabular}

الجدول السابق يبين أنه يوجد فروق ذات دلالة إحصائية بين آراء أفر اد العينـة يعزى العادي

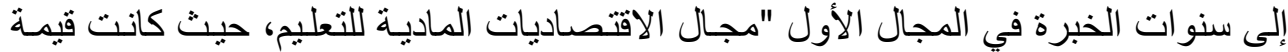

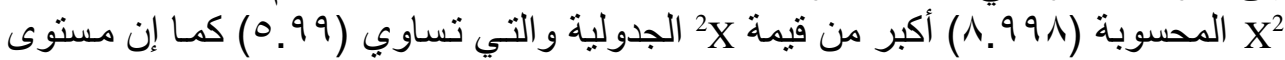

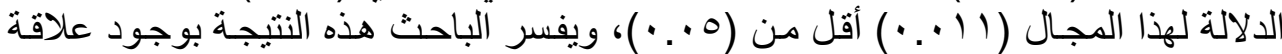
عكسية بين عدد سنوات الخبرة وبين مجال الاقتصاديات المادية للتعليه.

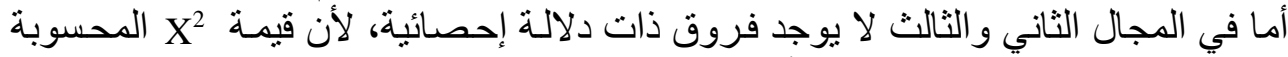

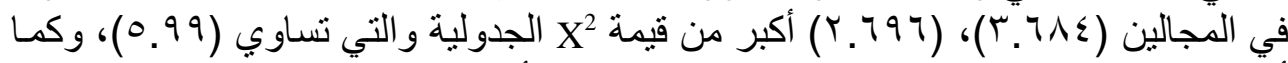

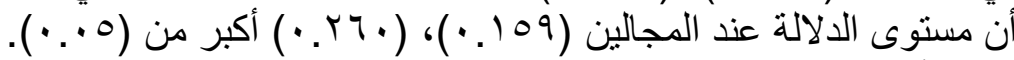

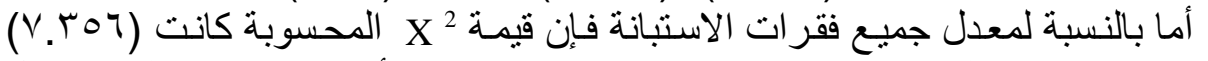

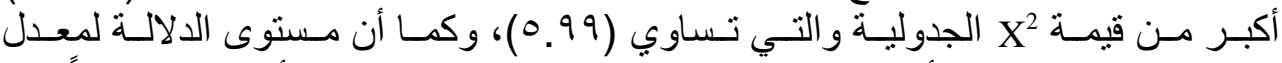

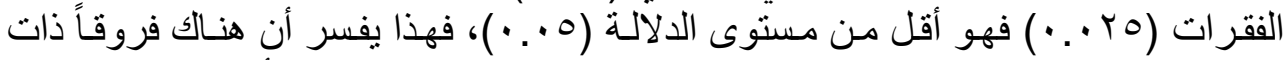

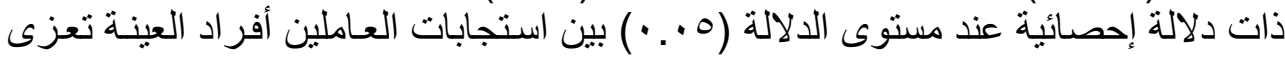
إلى متغير سنوات الخبرة. 


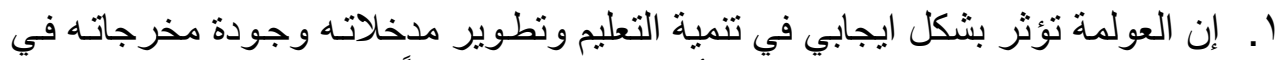

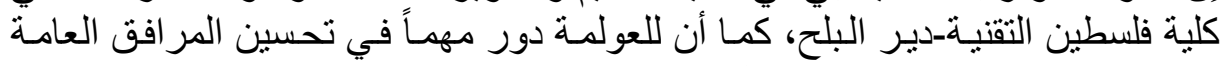
و ومباني ومختبر ات وقاعناعات كلية فلسطين التقنية.

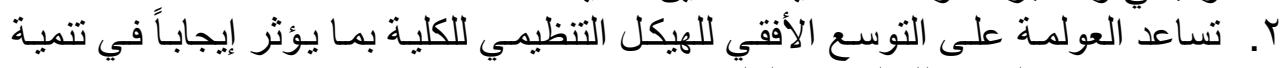
الاقتصاديات المادية للتعليم في الكلية.

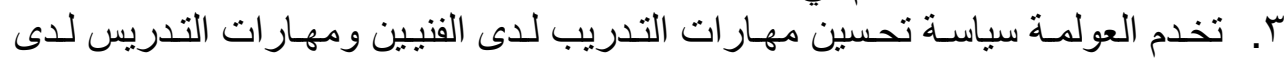
الأكاديمبين.

ع. تساعد العولمة إدارة الكلية في اتخاذ القرار ات وفي إيجاد استر اتيجيات سليمة وبديلة

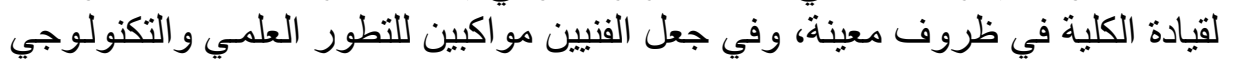
في كلية فلسطين التقنية.

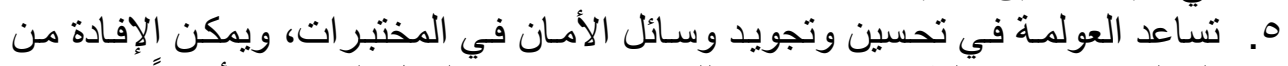

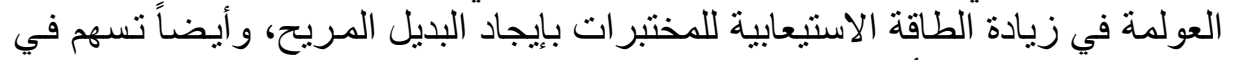
جعل مختبرات الكلية أكثر مو اكبة لمعايير الجودة العالية لالمية.

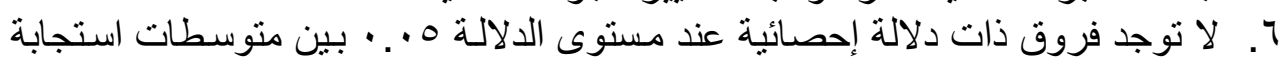

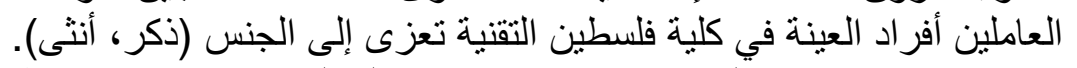

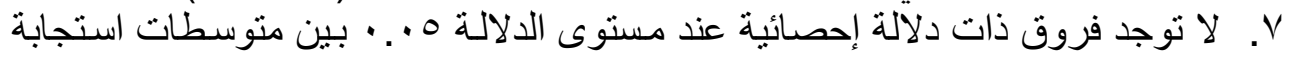

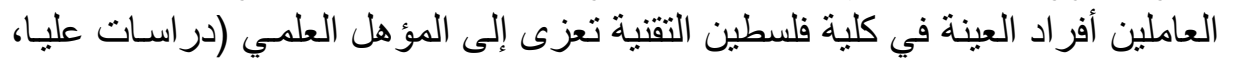
بكالوريوس، دبلوم).

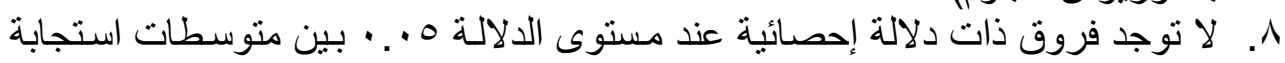

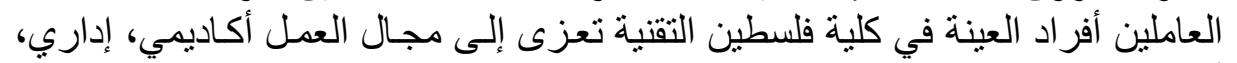
أكاديمي بمنصب إدادي).

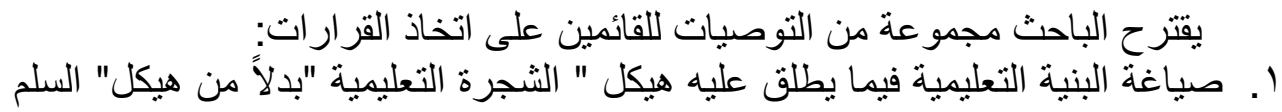
ثانياً- التوصيات

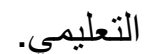
r. التركيز على اقتصاديات التعليم لنتيجة القرارات التقنية على رأي سيادة التلقين.

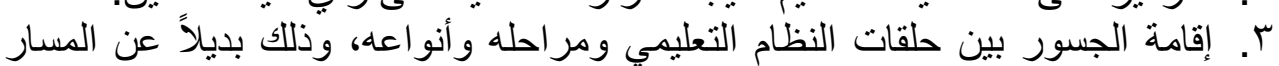

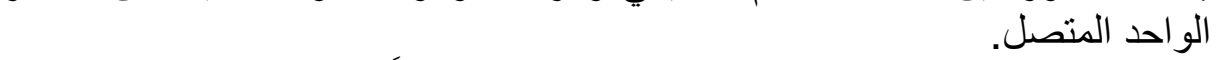
ع. التأكيد على القدرات الذهنيـة للتعامل مـع المجهول، بديلاً عن الاقتصـار على مجرد

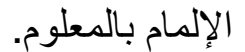

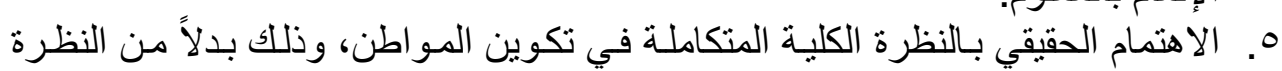

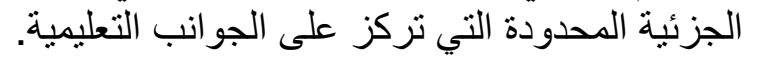

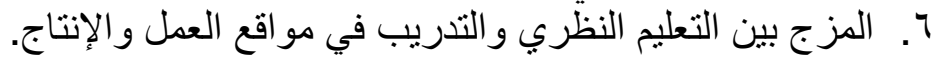

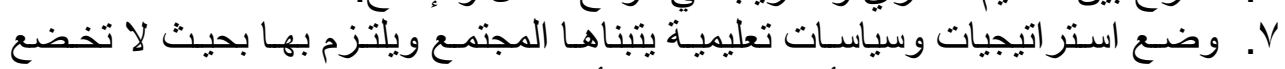

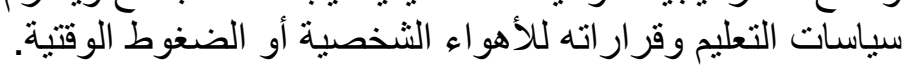

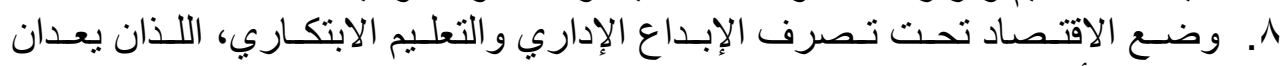
ركيزتين أساسيتين للحفاظ علي الجودة. 


\section{[الاغاغ]ara}

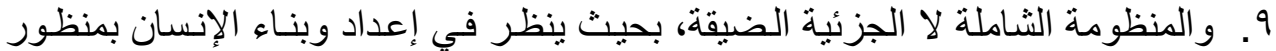
شمولي وتكاملي، ولا يقتصر على الجانب التحصيلي أو التعليمي، بالإضافة إلى النى النظر في عناصر المنظمة التعليمية بمر احلها ومستوياتها ككل متكامل.

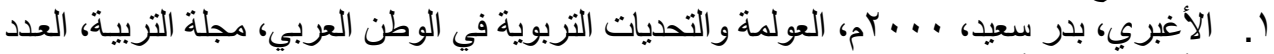

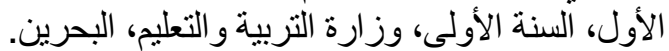

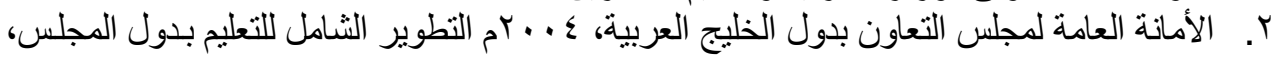

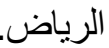

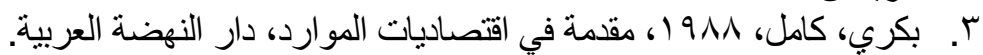

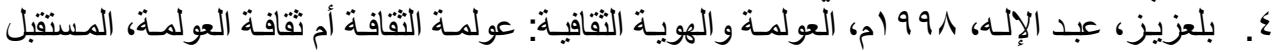

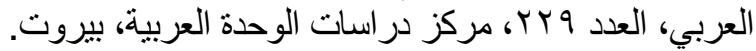

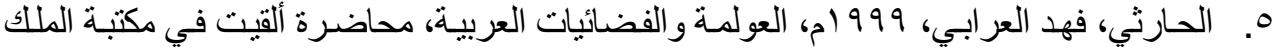

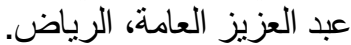

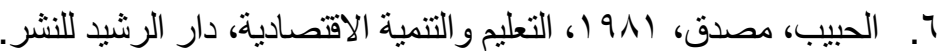

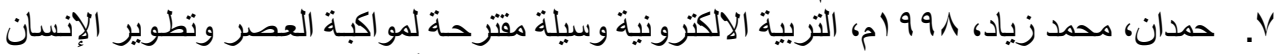

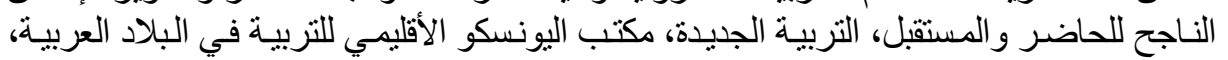

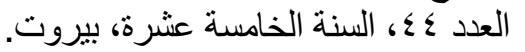

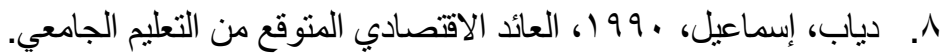

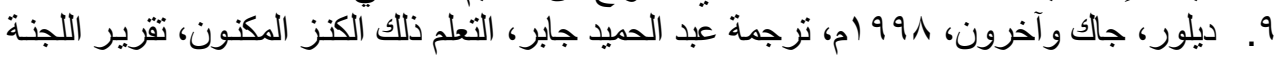

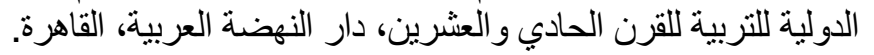

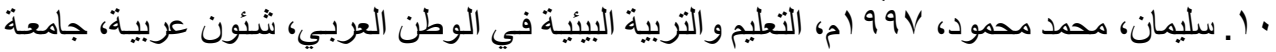

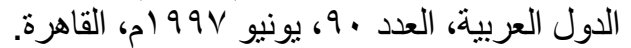

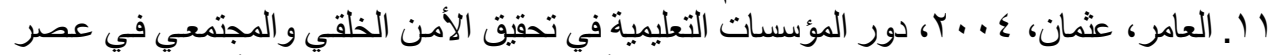

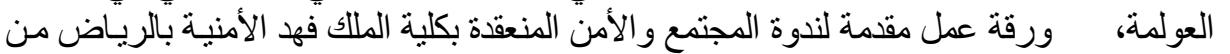

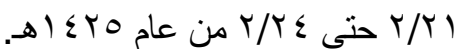

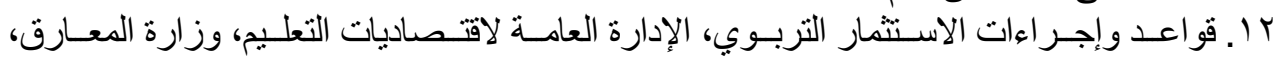

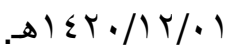

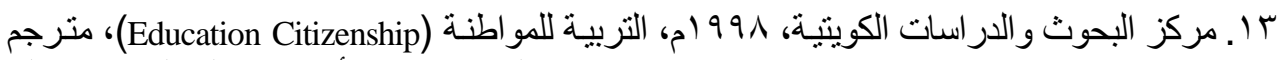

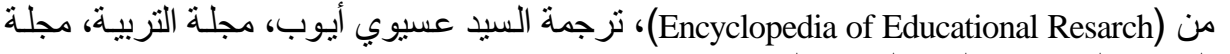
التربية، العدد ؟ ب، السنة الثامنة، الكويت.

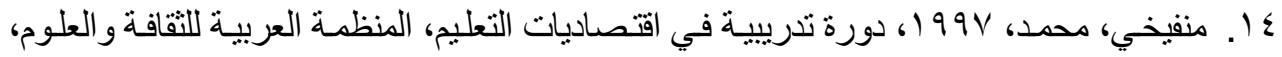
دمشق.

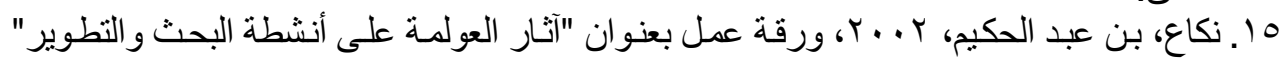

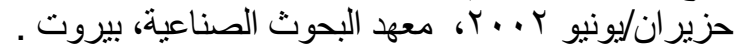

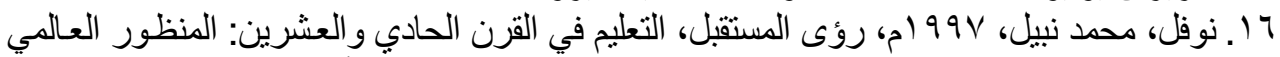

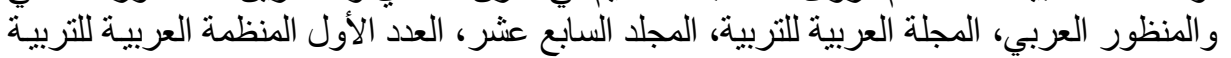

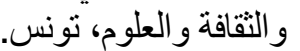
IV يسري، عبد الرحمن، تطور الفكر الاقتصادي. 


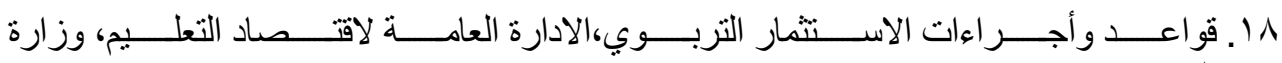

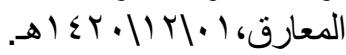

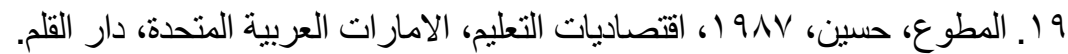

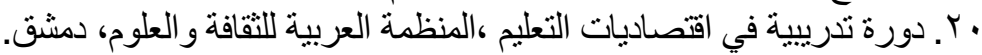

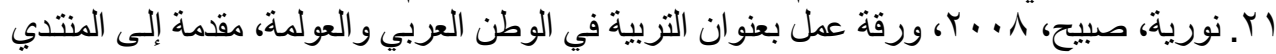

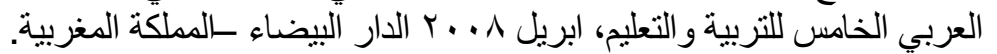

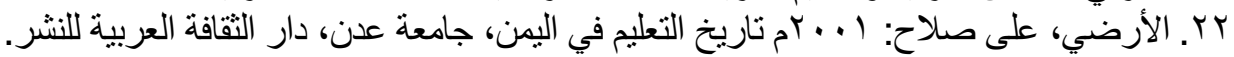

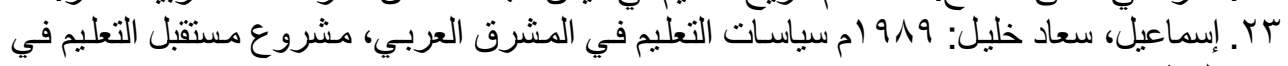

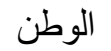

ـ ז. الإكليل: 911 ام مجلة دورية تعنى بتاريخ اليمن الفكري و الحضاري، العدد الأول، السنة السادسة

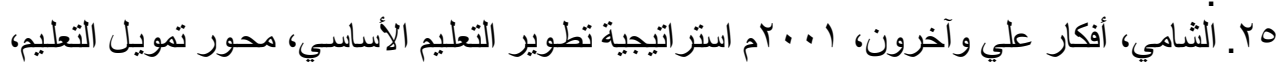

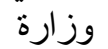

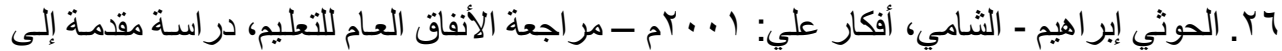

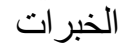

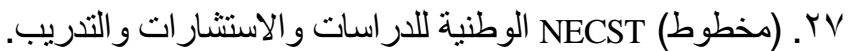

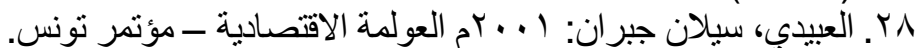

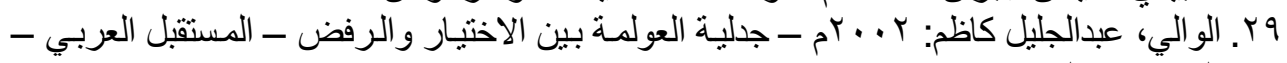

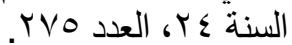

\section{ثانياً المراجع باللغة الأجنبية}

1. Bartlett, C. and S. Ghoshal, 1999, Managing Across Borders: Boston, Harvard, Business School Press.

2. Birkinshaw, J. and A. Morrison, 1995, Structural and Competitive Determinants, Strategic Management Journal No 16

3. Hamel, G and C.K. Prahalad, Competing For the future, Boston, Havrard, Business School Press.

http://www.arab-

ency.com/index.php?module=pnEncyclopedia\&func=display_term $\&$ id $=652 \&$ vid $=$ 